\title{
Atomic oxygen retrievals in the MLT region from SCIAMACHY nightglow limb measurements
}

\author{
O. Lednyts'kyy ${ }^{1}$, C. von Savigny ${ }^{1}$, K.-U. Eichmann ${ }^{2}$, and M. G. Mlynczak ${ }^{3}$ \\ ${ }^{1}$ Institute of Physics, Ernst-Moritz-Arndt-University of Greifswald, Greifswald, Germany \\ ${ }^{2}$ Institute of Environmental Physics, University of Bremen, Bremen, Germany \\ ${ }^{3}$ NASA Langley Research Center, Hampton, VA, USA \\ Correspondence to: O. Lednyts'kyy (olexandr.lednytskyy@uni-greifswald.de)
}

Received: 10 September 2014 - Published in Atmos. Meas. Tech. Discuss.: 30 October 2014

Revised: 30 January 2015 - Accepted: 6 February 2015 - Published: 4 March 2015

\begin{abstract}
Vertical distributions of atomic oxygen concentration $([\mathrm{O}])$ in the mesosphere and lower thermosphere (MLT) region were retrieved from sun-synchronous SCIAMACHY/Envisat (SCanning Imaging Absorption spectroMeter for Atmospheric CHartographY on board the Environmental Satellite) limb measurements of the oxygen $557.7 \mathrm{~nm}$ green line emission in the terrestrial nightglow. A band pass filter was applied to eliminate contributions from other emissions, the impact of measurement noise and auroral activity. Vertical volume emission rate profiles were retrieved from integrated limb-emission rate profiles under the assumption that each atmospheric layer is horizontally homogeneous and absorption and scattering can be neglected. The radiative transfer problem was solved using regularized total least squares minimization in the inversion procedure. Atomic oxygen concentration profiles were retrieved from data collected for altitudes in the range $85-105 \mathrm{~km}$ with approximately $4 \mathrm{~km}$ vertical resolution during the time period from August 2002 to April 2012 at approximately 22:00 local time. The retrieval of $[\mathrm{O}]$ profiles was based on the generally accepted two-step Barth transfer scheme including consideration of quenching processes and the use of different available sources of temperature and atmospheric density profiles. A sensitivity analysis was performed for the retrieved $[\mathrm{O}]$ profiles to estimate maximum uncertainties assuming independent contributions of uncertainty components. Errors in photochemical model parameters depending on temperature uncertainties and random errors of model parameters contribute less than $50 \%$ to the overall $[\mathrm{O}]$ retrieval error. The retrieved $[\mathrm{O}]$ profiles were compared with reference $[\mathrm{O}]$ profiles provided by SABER/TIMED (Sounding of the At-
\end{abstract}

mosphere using Broadband Emission Radiometry instrument on board the Thermosphere, Ionosphere, Mesosphere Energetics and Dynamics satellite) or by the NRLMSISE-00 (Naval Research Laboratory Mass Spectrometer and Incoherent Scatter radar Extended model, year: 2000) and SDWACCM4 (Whole Atmosphere Community Climate Model with Specified Dynamics, version 4). A comparison of the retrieved $[\mathrm{O}]$ profiles with the reference $[\mathrm{O}]$ profiles led to the conclusion that the photochemical model taking into account quenching of $\mathrm{O}\left({ }^{1} \mathrm{~S}\right)$ by $\mathrm{O}_{2}, \mathrm{O}\left({ }^{3} \mathrm{P}\right)$, and $\mathrm{N}_{2}$ and the SABER/TIMED model as a source of temperature and density profiles are the most appropriate choices for our case. The retrieved $[\mathrm{O}]$ profile time series exhibits characteristic seasonal variations in agreement with satellite observations based on analysis of $\mathrm{OH}$ Meinel band emissions and atmospheric models. A pronounced 11-year solar cycle variation can also be identified in the retrieved atomic oxygen concentration time series.

\section{Introduction}

Atomic oxygen $(\mathrm{O})$ is the most abundant chemically active trace gas in the Earth's mesosphere/lower thermosphere (MLT) region. It plays a critical role for $\mathrm{O}_{3}$ and indirectly for $\mathrm{OH}^{*}$ formation as well as the energy balance in the MLT region. Being generated through photolysis of molecular oxygen by ultraviolet radiation during daytime, atomic oxygen is subsequently destroyed through three-body recombination and other chemical processes. Atomic oxygen fuels exothermic chemical reactions (Mlynczak and Solomon, 
1993) and causes radiative cooling of the MLT region that occurs through collisions of $\mathrm{O}$ with molecules $\left(\mathrm{CO}_{2}, \mathrm{NO}\right)$, later resulting in infrared emissions (Jursa, 1985). The green line emission of $\mathrm{O}\left({ }^{1} \mathrm{~S}-{ }^{1} \mathrm{D}\right)$ is visible at night due to the long photochemical lifetime (on the order of months at $100 \mathrm{~km}$ altitude) of ground state atomic oxygen $\mathrm{O}\left({ }^{3} \mathrm{P}\right)$, which is excited to $\mathrm{O}\left({ }^{1} \mathrm{~S}\right)$ through the two-step process known as the Barth transfer scheme.

Decades of ground-based observations of the $\mathrm{O}\left({ }^{1} \mathrm{~S}-{ }^{1} \mathrm{D}\right)$ airglow emission rate (first performed by the fourth Baron Rayleigh in 1928; Egerton, 1949) were followed by rocket measurements. Ground-based observations of integrated airglow emission rates are constrained by specific geophysical locations for a given day. A limited number of direct measurements of atomic oxygen concentration ([O]) profiles (McDade et al., 1986; Iwagami et al., 2003; Yoshimura et al., 2003; Melo et al., 1996; Gobbi et al., 1992; Kita et al., 1992) were performed to support the hypothesis that a Barth-type mechanism is involved in producing $\mathrm{O}\left({ }^{1} \mathrm{~S}\right)$ in the MLT region. Simultaneous direct measurements of atomic oxygen density and nightglow emission rate profiles were provided by the Energy Transfer in the Oxygen Nightglow (ETON) rocket campaign to develop the well-known empirical airglow models (e.g., McDade et al., 1986).

Satellite limb measurements of the atomic oxygen $557.7 \mathrm{~nm}$ green line emission rates enable the continuous retrieval of [O] profiles and on a near-global basis. The SCanning Imaging Absorption spectroMeter for Atmospheric CHartographY (SCIAMACHY) on board the Environmental Satellite (Envisat) observed the atmosphere in a dedicated mesosphere/thermosphere limb mode that enabled vertically resolved measurements of the nightglow green line emission to be made. On the basis of the obtained measurements the retrieval of [O] profiles is possible.

The basic purpose of our study is such a retrieval of [O] profiles in the MLT region within the time period from $\mathrm{Au}-$ gust 2002 to April 2012 at approximately 22:00 local time (LT). The retrieval was performed according to the following scheme. The $\mathrm{O}\left({ }^{1} \mathrm{~S}-{ }^{1} \mathrm{D}\right)$ nighttime green line spectra measured by SCIAMACHY were averaged (see Sect. 2.1) and integrated to limb-emission rate (LER) profiles in $5^{\circ}$ latitude bins with daily and monthly resolution (see Sect. 3). Vertical volume emission rate (VER) profiles were retrieved from LER profiles applying linear inversion supported by regularized total least squares (RTLS) minimization (see Sect. 4). The well-known cubic equation (McDade et al., 1986) and its extension (Gobbi et al., 1992; Semenov, 1997; Khomich et al., 2008) were used to retrieve [O] profiles (see Sect. 5) on the basis of temperature and density profiles provided by different available sources and VER profiles retrieved from SCIAMACHY nightglow observations. Temperature and density profiles were provided by the Naval Research Laboratory Mass Spectrometer and Incoherent Scatter radar Extended model, year: 2000, (NRLMSISE-00) semiempirical atmospheric model (Picone et al., 2002), the Whole
Atmosphere Community Climate Model with Specified Dynamics, version 4, (SD-WACCM4) model (Liu et al., 2010) and by measurements with the Sounding of the Atmosphere using Broadband Emission Radiometry (SABER) instrument (Mlynczak, 1997; Russell et al., 1999) on the Thermosphere, Ionosphere, Mesosphere Energetics and Dynamics (TIMED) spacecraft.

Random and systematic errors were estimated for the obtained data sets at each step of the retrieval. The uncertainty components were assumed to contribute to the total error independently. Successive linear addition of the estimated uncertainty components (Kennedy et al., 2011) was performed at each step of the retrieval procedure to calculate the maximum error. A verification of the retrieved [O] profiles was performed through their comparison with reference [O] profiles provided by the NRLMSISE-00 and SDWACCM4 models as well as SABER retrievals (see Sect. 6). A selection of the appropriate photochemical model (cubic or extended cubic equation) and the choice of the appropriate source of temperature and density profiles was made at the corresponding steps of the verification.

The optimized [O] retrieval (based on VER profiles provided by SCIAMACHY measurements, see Sect. 5) might also be applied to VER profiles provided by other satellite instruments: e.g., Wind Imaging Interferometer (WINDII), Optical Spectrograph and Infrared Imager System (OSIRIS) and Imager of Sprites and Upper Atmospheric Lightning (ISUAL). Hydroxyl and oxygen green line nightglow observations from the WINDII on board the Upper Atmosphere Research Satellite from 1991 to 2004 were already used to retrieve [O] profiles (Russell et al., 2005). Daytime and nighttime $\mathrm{O}_{2}$ A-band airglow measurements with the OSIRIS on board the Odin satellite from 2001 to date were also used to retrieve [O] profiles (Sheese et al., 2011). Gao et al. (2012) used green line airglow measurements with the ISUAL on board the FORMOSAT-2 satellite to retrieve [O] profiles. In a very recent study, SCIAMACHY O $\left({ }^{1} \mathrm{~S}-{ }^{1} \mathrm{D}\right)$ green line observations were employed by Kaufmann et al. (2014) in combination with a slightly modified version of the McDade et al. (1986) photochemical model to retrieve atomic oxygen profiles. Differences between the Kaufmann et al. (2014) retrieval and the one presented in this study will be discussed below in Sect. 7.3.

\section{Description of instruments and models used}

\subsection{SCIAMACHY on board the satellite Envisat}

The Envisat-1 designed by the European Space Agency carries 10 instruments (total weight about 8 tons). One of them, SCIAMACHY (Burrows et al., 1995; Bovensmann et al., 1999), observed the atmospheric radiation field in limb, nadir and solar/lunar occultation geometry. On 1 March 2002 Envisat was launched into a sun-synchronous orbit with an 
inclination of $98.5^{\circ}$ and a period of $100 \mathrm{~min}$, thus performing about 14.4 orbits per day at a mean altitude of $799.8 \mathrm{~km}$ (Gottwald et al., 2006). The grating spectrometer SCIAMACHY provided measurements in eight spectral channels within a wavelength range of $220-2380 \mathrm{~nm}$ and a spectral resolution of $0.22-1.48 \mathrm{~nm}$.

The limb-emission observations on the Earth's nightside additionally performed by SCIAMACHY at a fixed local solar time (around 22:00 LT) were used in the study presented here. This dedicated mesosphere/thermosphere mode, covering the $75-150 \mathrm{~km}$ tangent height range, is characterized by a nominal difference between two adjacent tangent heights of $3.3 \mathrm{~km}$ and $0.045^{\circ}$ vertical field of view (Cardaci, 2010; Kaiser et al., 2004). The geometrical field of view is approximately $2.4-2.6 \mathrm{~km}$ in the vertical direction at the tangent point depending on tangent height and satellite altitude (Kaiser et al., 2004). Note that the SCIAMACHY nighttime limb-emission measurements are performed continuously throughout the year only at latitudes between 0 and $30^{\circ} \mathrm{N}$.

The communication link to Envisat-1 and hence SCIAMACHY operations was interrupted in April 2012. The nighttime limb measurements from August 2002 to April 2012 were pre-processed by the German Aerospace Center (DLR) and data quality reports (SOST-DLR, 2013a, b, c), and data anomaly reports (SOST-DLR, 2012) were provided. The data used in our study were pre-processed from Level 1c SCIAMACHY format to the orbital measurements of the green line emission spectra. Level 1 data version 7.0x were used in this study and the data were calibrated using all calibration flags (Gottwald et al., 2006) required to obtain fully calibrated SCIAMACHY limb radiances. The spectral resolution of the SCIAMACHY spectra in channel three used in this study is about $0.2 \mathrm{~nm}$.

\subsection{SABER on board the satellite TIMED}

SABER infrared radiometer (Mlynczak, 1997; Russell et al., 1999) on board the National Aeronautics and Space Administration (NASA) TIMED satellite measures a number of middle atmospheric parameters and NASA provides the data online via their website (SABER, 2014). SABER measurements are made within the latitude range $54^{\circ} \mathrm{S}-87^{\circ} \mathrm{N}$ or $87^{\circ} \mathrm{N}-54^{\circ} \mathrm{S}$ with coverage alternating every 60 days. The vertical resolution of SABER measurements is approximately $2 \mathrm{~km}$ (Mertens et al., 2009). Nighttime hydroxyl emission rates measured with SABER are used to calculate atomic oxygen mixing ratios (Mlynczak et al., 2013). In our study, SABER level 2A data (version 2.0) for the years 2002-2012 were interpolated to $1.0 \mathrm{~km}$ altitude grid resolution and averaged within the time interval 21:00-23:00 LT to compare them with SCIAMACHY measurements made at around 22:00 LT. Atmospheric density and temperature profiles provided by SABER were used in the SCIAMACHY [O] retrieval as discussed in Sect. 5. The concentrations of molecular oxygen $\left(\left[\mathrm{O}_{2}\right]\right)$ and molecular nitrogen $\left(\left[\mathrm{N}_{2}\right]\right)$ were calculated from atmospheric density profiles assuming constant mixing ratios. The decrease of the $\left[\mathrm{O}_{2}\right] /\left[\mathrm{N}_{2}\right]$ ratio with altitude according to NRLMSISE-00 data is not reliable as pointed out by Picone et al. (2002), because credible mesospheric $\left[\mathrm{O}_{2}\right]$ data are absent in the NRLMSISE-00 database. If the mixing ratio correction based on NRLMSISE-00 $\left[\mathrm{O}_{2}\right]$ and $\left[\mathrm{N}_{2}\right]$ profiles were applied in our O retrieval, SCIAMACHY [O] values would fall by $4 \%$ in the altitude range $100-105 \mathrm{~km}$. We supposed in our SCIAMACHY O retrieval that a constant mixing ratio is valid at altitudes up to $105 \mathrm{~km}$, which is also assumed in the SABER O retrieval (Smith, 2010). The atomic oxygen mixing ratio profiles based on SABER measurements were converted into [O] profiles and used as reference $[\mathrm{O}]$ profiles for the verification of the retrieved [O] profiles (see Sect. 7).

\subsection{NRLMSISE-00 and SD-WACCM4 models}

NRLMSISE-00 incorporates ground-based, rocket and satellite-borne measurements. A set of parametric equations of diffusive equilibrium (Akins et al., 2003) is used to interpolate or extrapolate the data. Heliogeophysical conditions which influence the parameters relevant for the photochemical model were employed for the [O] retrieval in our study. These parameters, F10.7 (10.7 cm solar radio flux) and Ap-index (planetary equivalent daily amplitude), were taken from databases provided by the National Oceanic and Atmospheric Administration (NOAA, 2014a). The NRLMSISE00 model provided online (NRLMSISE-00, 2014) was used to simulate the concentration profiles of individual atmospheric constituents (i.e., $[\mathrm{O}],\left[\mathrm{O}_{2}\right],\left[\mathrm{N}_{2}\right]$ ) and temperature profiles for the specifically chosen heliogeophysical conditions and geographical locations at 22:00 LT with $1.0 \mathrm{~km}$ altitude grid resolution.

In this study we also use atomic oxygen and atmospheric background parameters modeled with SD-WACCM4; see Garcia et al. (2007) for a description of a previous version of the model. SD-WACCM4 is nudged to Goddard Earth Observing System Model, version 5, (GEOS-5) meteorological fields below about $50 \mathrm{~km}$ altitude. The SD-WACCM4 data set used in this study covers the period from April 2010 to March 2011 and was previously also employed by Hoffmann et al. (2012) and Kowalewski et al. (2014). The geopotential height profiles provided by SD-WACCM4 were converted to geometrical height profiles. Temperature profiles, atmospheric pressure profiles and [O] profiles were interpolated from the geometrical height grid to an altitude grid with $1.0 \mathrm{~km}$ resolution. The $\left[\mathrm{O}_{2}\right]$ and $\left[\mathrm{N}_{2}\right]$ profiles required for the present study were calculated from SD-WACCM4 pressure and temperature profiles assuming the ideal gas law and constant $\mathrm{O}_{2}$ and $\mathrm{N}_{2}$ mixing ratios. To extract the required atmospheric parameters at 22:00 LT we sampled the corresponding longitude of the SD-WACCM4 output provided 


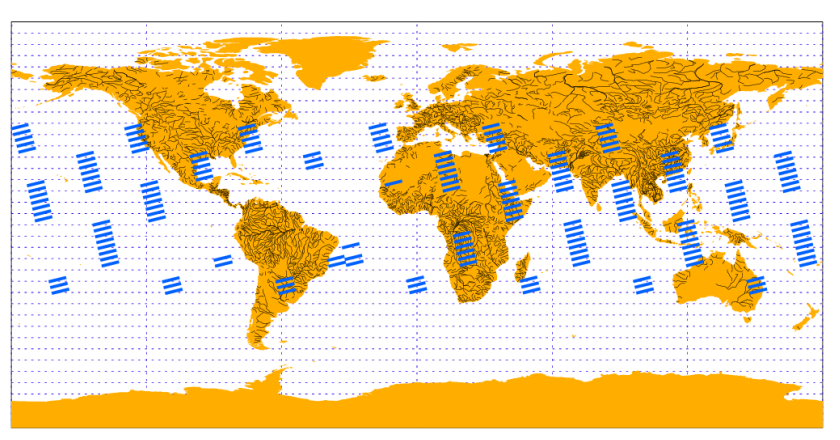

Figure 1. Geographical location and coverage of nighttime limbemission observations performed by SCIAMACHY on 9 September 2010 in the dedicated mesosphere/thermosphere mode.

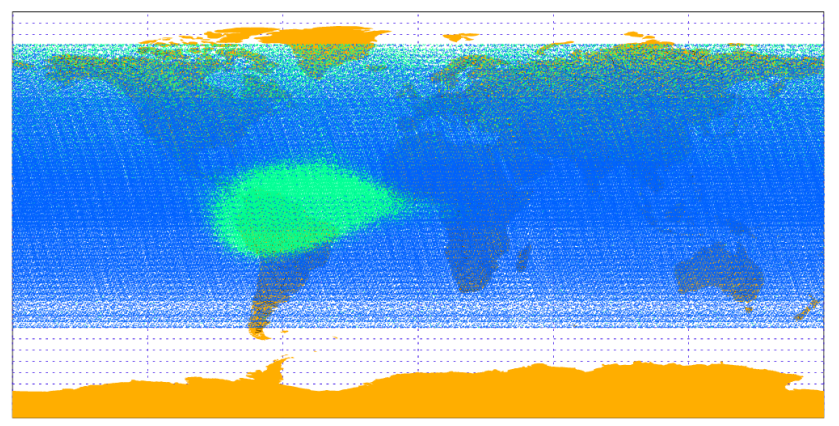

Figure 2. Geographical locations of nighttime limb-emission observations performed by SCIAMACHY between 2 August 2002 and 8 April 2012. Limb measurements marked in green are excluded because they are affected by Aurora Borealis, highly energetic particles in the South Atlantic Anomaly or by an enhanced offset possibly related to contaminating emissions associated with the $\mathrm{OH}(7-$ 1) transition (Blackwell et al., 1960) and the $\mathrm{NO}+\mathrm{O}$ air-afterglow continuum (e.g., von Savigny et al., 1999).

with daily resolution at 00:00 UTC, as in Kowalewski et al. (2014).

\section{Determination of green line limb-emission profiles}

The nightglow limb spectral measurements provided by SCIAMACHY were screened and measurements from certain orbits were excluded according to measurement errors presented in the SOST-DLR quality and anomaly reports (SOST-DLR, 2013a, b, c, 2012; see Sect. 2.1).

The geographical position and extent of the air volumes observed by SCIAMACHY nighttime limb measurements on a single day are presented in Fig. 1. The duration of a single measurement is about $60 \mathrm{~s}$ and the horizontal resolution is about $1000 \mathrm{~km} \times 630 \mathrm{~km}$. The geographical positions of all nighttime limb measurements performed during the period from 2 August 2002 to 8 April 2012 are shown in Fig. 2. For the retrieval we used the limb measurements marked in blue in Fig. 2 but not the measurements that are affected by Aurora

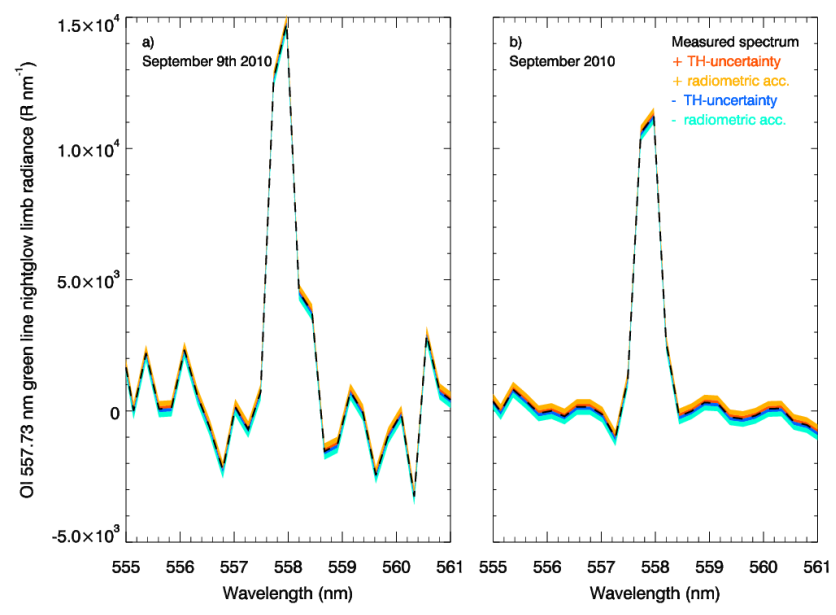

Figure 3. Sample daily (a) and monthly (b) averaged green line emission spectra (calculated by averaging 12 (a) and 480 (b) orbital spectral measurements) at $95 \mathrm{~km}$ altitude for the $20-25^{\circ} \mathrm{N}$ latitude range with uncertainty components $\sigma_{h}^{+}$(orange), $\sigma_{a}^{+}$(yellow), $\sigma_{h}^{-}$ (light blue) and $\sigma_{\bar{a}}^{-}$(cyan). See Sects. 3 and 6.1 for further details.

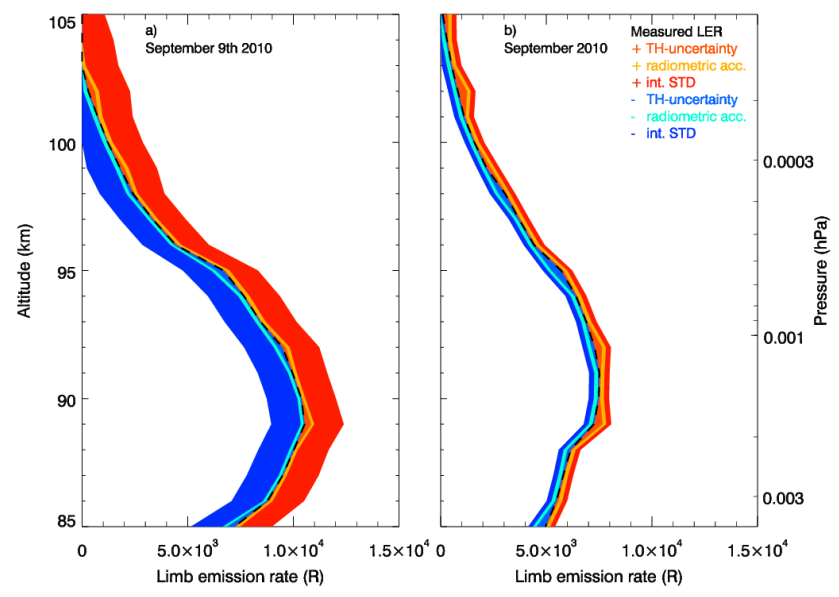

Figure 4. Sample daily (a) and monthly (b) averaged green line LER profiles for the $20-25^{\circ} \mathrm{N}$ latitude range with uncertainty components $\boldsymbol{\sigma}_{h}^{+}$(orange), $\boldsymbol{\sigma}_{a}^{+}$(yellow) introduced for determining $\boldsymbol{P}_{+1}$ and calculated for $\boldsymbol{L} \boldsymbol{E} \boldsymbol{R}_{+1}$ and $\sigma_{l}$ (red) calculated directly for $\boldsymbol{L} \boldsymbol{E} \boldsymbol{R}_{+1}$. Similarly, $\boldsymbol{\sigma}_{h}^{-}$(light blue) and $\boldsymbol{\sigma}_{\bar{a}}^{-}$(cyan) are introduced when calculating $\boldsymbol{P}_{-1}$ and are propagated to determine $\boldsymbol{L} \boldsymbol{E} \boldsymbol{R}_{-1}$. $\sigma_{l}$ (blue) is directly calculated for $\boldsymbol{L} \boldsymbol{E} \boldsymbol{R}_{-1}$. See Sects. 3 and 6.1 for further details.

Borealis, by highly energetic particles or by contaminating emissions.

The measured spectra within the tangent height range from 75 to $128 \mathrm{~km}$ with $3.3 \mathrm{~km}$ vertical sampling were interpolated to $1.0 \mathrm{~km}$ altitude grid resolution within the spectral range $555-561 \mathrm{~nm}$. For each individual spectrum the emission spectra averaged over the $110-126 \mathrm{~km}$ tangent height range were subtracted from the spectrum at each tangent height. The subtraction of the $110-126 \mathrm{~km}$ average is because 
of contributions from other emissions, the impact of noise and auroral activity. Then each spectrum was separated into three parts corresponding to the following wavelength intervals: from 555 to $557 \mathrm{~nm}$ (background emissions and noise), from 557 to $559 \mathrm{~nm}$ (green line emission) and from 559 to $561 \mathrm{~nm}$ (background emissions and noise) (see Fig. 3). The spectral baseline underneath the green line was determined using the background and noise intervals and was subtracted from the spectral data in the green line interval. Each individual spectrum was analyzed with the help of a band pass filter based on the application of variance and mean value thresholds within the wavelength intervals from 555 to $557 \mathrm{~nm}$ and from 559 to $561 \mathrm{~nm}$. Measurement noise detection based on the variance threshold was only applied within the wavelength interval from 557 to $559 \mathrm{~nm}$. The empirical choice and application of the threshold values are discussed below.

Envisat, as it passes through the South Atlantic Anomaly at an altitude of approximately $800 \mathrm{~km}$, is exposed to highenergy particles within the lowest of the three Van Allen belts. The varying solar activity (Hudson et al., 2008) and solar coronal mass ejections, e.g., the Halloween event in 2003, caused measurement interruptions (reported by SOSTDLR in data quality and anomaly reports). Spectra were excluded from the retrieval if the variance within the background wavelength intervals exceeded the variance threshold value of $50 \times 10^{6}$ Rayleigh ${ }^{2} \mathrm{~nm}^{-2}$ (1 Rayleigh equals $10^{10}$ photon $\mathrm{s}^{-1} \mathrm{~m}^{-2}$ ).

The geographical position of limb spectral measurements was used to exclude them from further processing in the case when contamination by auroral events was expected. The size of the auroral oval (Newell et al., 2002) varies constantly with each minute depending on the hemispheric power index provided by NOAA (2014b) that was used as a measure of the auroral activity in this study. The shape of the aurora oval was approximated with a circle centered at the north geomagnetic pole $\left(80^{\circ} \mathrm{N}, 72^{\circ} \mathrm{W}\right)$ according to the International Geomagnetic Reference Field (IGRF-11) model. The area of such a circle is supposed to vary according to the value of the hemispheric power index so that spectra measured at geographical locations within this circle were excluded from daily and monthly averaging. In addition to this aurora position filter, the variance threshold value of $60 \times 10^{6}$ Rayleigh $^{2} \mathrm{~nm}^{-2}$ was also applied within the green line wavelength interval to exclude non-valid spectral measurements.

The Q and $\mathrm{P}$ branch components of the $\mathrm{OH}(7-1)$ band emissions (Blackwell et al., 1960) can contribute to the green line emissions within the wavelength interval from 555 to $561 \mathrm{~nm}$. There are no other sources of nightglow emissions contributing to the spectra of the analyzed green line emissions to be additionally considered, except the one due to the $\mathrm{NO}+\mathrm{O}$ air-afterglow reaction, which is, however, typically at least 2 orders of magnitude weaker than the $\mathrm{O}\left({ }^{1} \mathrm{~S}\right)$ green line (von Savigny et al., 1999). These contaminating emissions may affect the spectral baseline. Spectra were excluded from the retrieval if the absolute mean value in the background wavelength intervals exceeded the threshold value of 500 Rayleigh nm ${ }^{-1}$. Figure 3 presents sample daily (a) and monthly (b) spectra that are calculated by averaging 12 (a) and 480 (b) orbital spectral measurements at the altitude of $95 \mathrm{~km}$ in the latitude range $20-25^{\circ} \mathrm{N}$. Each spectral measurement processed was integrated over the green line wavelength interval from 557 to $559 \mathrm{~nm}$. The green line LER profiles were daily or monthly averaged and converted to Rayleigh. Zonal averaging in $5^{\circ}$ latitude bins was applied additionally because the zonal atmospheric motion in the MLT is much faster than the meridional motion. Daily and monthly averaged sample LER profiles within the latitude range 20$25^{\circ} \mathrm{N}$ are presented in Fig. 4.

\section{Retrieval of volume emission rate profiles}

The main task of this step of the retrieval procedure is to invert LER profiles (being a function of tangent height $h$ ) to vertical VER profiles (as a function of geometric altitude $z$ ), given that the elements of the LER profiles are integrals of the VER along the line of sight (LOS). The Earth's atmosphere, represented by the flattened Earth model WGS84 (e.g., NIMA, 2000; Larson and Wertz, 1999) is assumed to be composed of homogeneously emitting layers of $1 \mathrm{~km}$ thickness. The geometrical distances (optical paths) along the LOS passing through subsequent layers of the model atmosphere were calculated using the Pythagorean theorem.

A linear model was used to map (Rodgers, 2000) VER profiles from their state space into measurement space of LER profiles. Note that extinction due to scattering and selfabsorption is negligible for this specific application. The forward model is mathematically represented by the following linear relationship:

$\boldsymbol{y}=\mathbf{F}(\boldsymbol{x}, \boldsymbol{b})+\epsilon=\mathbf{K} \boldsymbol{x}+\epsilon$,

where LER profiles are represented by the measurement vector $\boldsymbol{y}, \mathrm{VER}$ profiles are represented by the state vector $\boldsymbol{x}, \mathbf{F}$ is the functional representation of the forward model, the vector term $\boldsymbol{b}$ represents the random error of model parameters (one of the model parameters relevant for this retrieval step is an offset in tangent height registration) and $\epsilon$ is a statistical uncertainty that includes both the uncertainty in $\boldsymbol{y}$ and in the elements of the weighting function matrix $\mathbf{K}$ (see Sect. 6). The inverse problem is even-determined for the chosen retrieval altitude grid resolution of $1.0 \mathrm{~km}$, being the same for the standard tangent height grid resolution.

A least squares method was employed to solve the inverse problem, minimizing the prediction error assuming linear system inconsistencies due to noise in $\boldsymbol{y}$. Phillips-Tikhonov regularization was chosen to avoid physically meaningless solutions such as oscillations due to, e.g., numerical sensitivity of the inversion. 

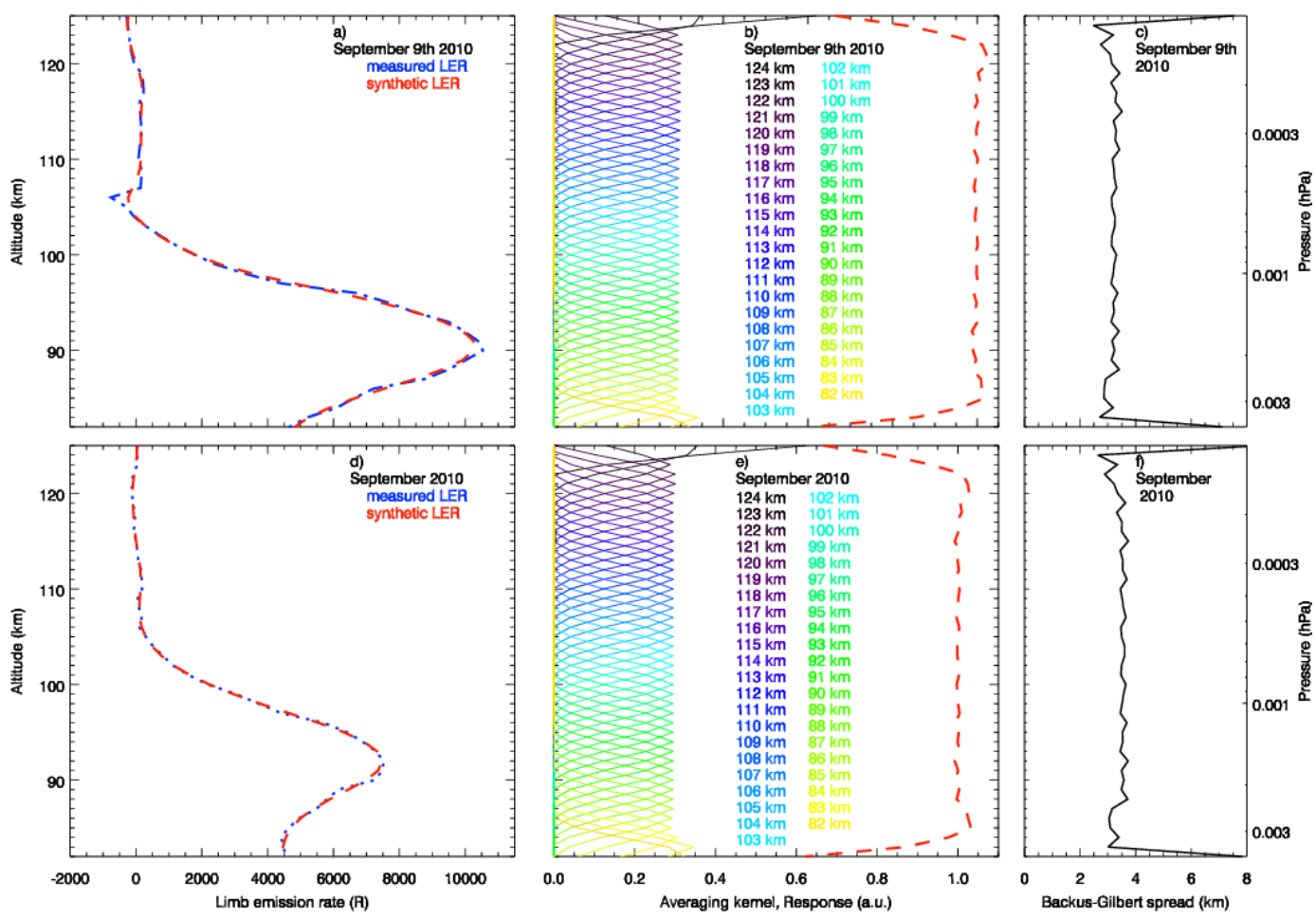

Figure 5. Characteristics and diagnostics of the inversion procedure in sample daily (top row) and monthly averages (bottom row) for the latitude range $20-25^{\circ} \mathrm{N}$ : comparison of the measured LER profile and the synthetic LER profile (panels a and d); averaging kernel and the resulting area (response curve marked red) (panels $\mathbf{b}$ and e); the vertical resolution (Backus-Gilbert spread) (panels $\mathbf{c}$ and f).

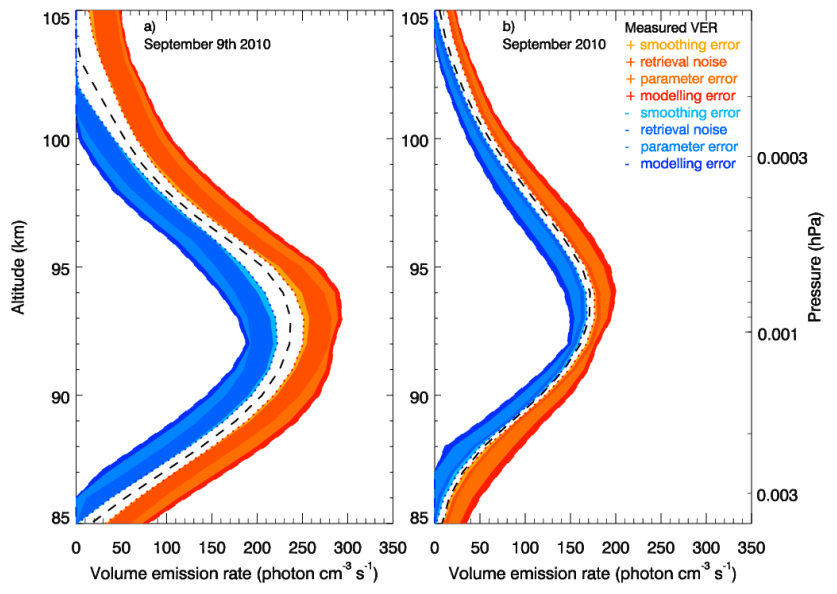

Figure 6. Sample daily (a) and monthly (b) averaged green line VER profiles for the $20-25^{\circ} \mathrm{N}$ latitude range with uncertainty $\left(\sigma_{\mathbf{S}_{\mathrm{tot}}}\right)$ components $\sigma_{\mathbf{S}_{\mathrm{s}}}$ (yellow), $\sigma_{\mathbf{S}_{\mathrm{m}}}$ (light red), $\sigma_{\mathbf{S}_{\mathrm{b}}}$ (orange), $\sigma_{\mathbf{S}_{\mathrm{f}}}$ (red) introduced and calculated for the $\boldsymbol{V} \boldsymbol{E} \boldsymbol{R}_{+1}$ retrieval, $\sigma_{\mathbf{S}_{\mathrm{s}}}$ (cyan marked), $\sigma_{\mathbf{S}_{\mathrm{m}}}$ (light blue), $\sigma_{\mathbf{S}_{\mathrm{b}}}$ (dark cyan) and $\boldsymbol{\sigma}_{\mathbf{S}_{\mathrm{f}}}$ (blue) introduced and calculated for the $\boldsymbol{V} \boldsymbol{E} \boldsymbol{R}_{-1}$ retrieval. See Sects. 4, 4.3, 6.1 and 7.1 for further details.
The determination of SCIAMACHY tangent heights is characterized by uncertainties, but the tangent height error drift is, at less than $20 \mathrm{myear}^{-1}$, very small (Bramstedt, 2012). Because the resulting tangent height uncertainties affect the weighting function matrix $\mathbf{K}$, the total least squares method with regularization was applied to reduce potential numerical instabilities and oscillations due to uncertainties in $\boldsymbol{y}$ and $\mathbf{K}$.

At first, an inversion was performed using a constrained least squares approach:

$\boldsymbol{x}=\left(\mathbf{K}^{\mathrm{T}} \mathbf{K}+\gamma_{\mathrm{r}} \mathbf{H}^{\mathrm{T}} \mathbf{H}\right)^{-1} \mathbf{K}^{\mathrm{T}} \boldsymbol{y}=\mathbf{G}_{\mathrm{r}} \boldsymbol{y}$,

where the positive semi-definite regularization matrix $\mathbf{H}$ (Wang and Yuan, 2003) is scaled with the regularization parameter $\gamma_{\mathrm{r}}$ (lower index $\mathrm{r}$ means "restricted", i.e., without considering $\mathbf{S}_{\mathrm{e}}$ and $\mathbf{S}_{\mathrm{a}}$ ) and the restricted gain matrix $\mathbf{G}_{\mathrm{r}}$ (also known as the generalized inverse matrix). To determine the value of $\gamma_{\mathrm{r}}$ the automated RTLS procedure (see Sect. 4.2) was applied.

At the next step, the diagonal noise covariance matrix $\mathbf{S}_{\mathrm{e}}$ (corresponding to the $1 \sigma$ error of the current LER profile $\boldsymbol{y}$ ) was introduced. Uncertainty information of measured LER profiles represented by $\mathbf{S}_{\mathrm{e}}$ needs to be appropriately balanced with the a priori covariance matrix $\mathbf{S}_{\mathrm{a}}$ related to the retrieved target VER profiles $\boldsymbol{x}$. The first-order linear Bayesian 


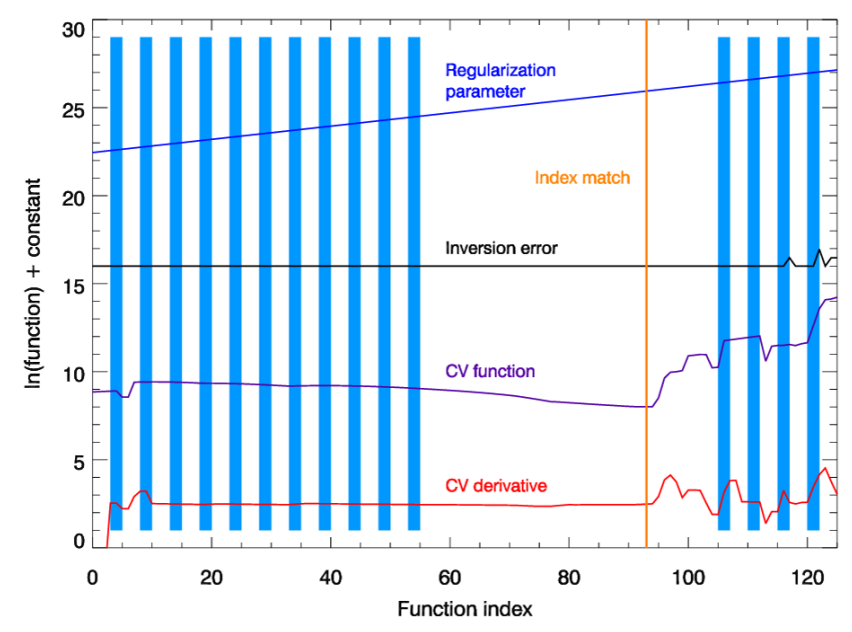

Figure 7. Illustration of the regularized total least squares (RTLS) minimization used for the identification of the optimal regularization parameter $\gamma_{\mathrm{r}}$. Shading (with vertical blue lines) of the regions in the range of possible regularization parameters means their rejection from the retrieval, absence of shading means their acceptance. The cross-validation (CV) function (see Eq. 9) is used to locate its minimum and to determine the index of $\gamma_{\mathrm{r}}$. Alternatively, the peak of the $\mathrm{CV}$ derivative occurring where the steepest slope of the $\mathrm{CV}$ function occurs can be used to locate the index of $\gamma_{r}$. The index of the optimal regularization parameter $\gamma_{\mathrm{r}}$ is marked by an orange line.

approach (Rodgers, 2000) was implemented to solve Eq. (3) extended with $\mathbf{S}_{\mathrm{e}}$ and $\mathbf{S}_{\mathrm{a}}$ (see Sect. 4.1).

\subsection{Implementation of the inversion procedure}

The maximum a posteriori solution obtained after generalization for independent components of the state vector $\boldsymbol{x}$ (Rodgers, 2000) is given by:

$\boldsymbol{x}=\mathbf{S}_{\mathrm{a}} \mathbf{K}^{\mathrm{T}}\left(\mathbf{K S}_{\mathrm{a}} \mathbf{K}^{\mathrm{T}}+\mathbf{S}_{\mathrm{e}}+\gamma \mathbf{H}^{\mathrm{T}} \mathbf{H}\right)^{-1} \boldsymbol{y}=\mathbf{G} \boldsymbol{y}$,

where the positive semi-definite regularization matrix $\mathbf{H}$ (Wang and Yuan, 2003) is scaled with the regularization parameter $\gamma$ and the retrieval gain matrix $\mathbf{G}$. The inversion procedure becomes insensitive to the application of covariance matrices if the a priori matrix $\mathbf{S}_{\mathrm{a}}$ is calculated with help of the $\mathbf{S}_{\mathrm{e}}$ matrix.

Under the assumption (based on similarities in statistical distributions of $\mathbf{S}_{\mathrm{a}}$ and $\mathbf{S}_{\mathrm{e}}$ for our case) that $\mathbf{S}_{\mathrm{a}}$ is calculated from $S_{e}$, Eq. (3) gives us

$\overline{\operatorname{diag}\left(\mathbf{K S}_{\mathrm{a}} \mathbf{K}^{\mathrm{T}}\right)} \approx \overline{\operatorname{diag}\left(\mathbf{S}_{\mathrm{e}}\right)}$.

A comparison of Eq. (2) and Eq. (3) gives that $\gamma, \gamma_{\mathrm{r}}$ and $\mathbf{S}_{\mathrm{a}}$ are related as follows:

$\gamma=\gamma_{\mathrm{r}} \cdot \overline{\operatorname{diag}\left(\mathbf{S}_{\mathrm{a}}\right)}$.

Once $\gamma_{\mathrm{r}}$ is determined (see Eq. 2) using the RTLS procedure (see Sect. 4.2), $\gamma$ can be calculated.
The presented $\gamma$ calculation procedure is supported by evident equivalence of the VER profiles retrieved according to Eq. (2) (optimized for using $\gamma_{\mathrm{r}}$ ) and Eq. (3) (optimized for using $\gamma$ ). The calculation procedure is supported also by the fact that the measurement vector $\boldsymbol{y}$ is similar to the synthetic vector $\boldsymbol{s}=\mathbf{K} \boldsymbol{x}$. In fact, the curve representing the synthetic vector $s$ fits the curve representing the measurement vector $\boldsymbol{y}$. The relative difference between $\boldsymbol{s}$ and $\boldsymbol{y}$ is less than 0.1 (or $10 \%$ ) for data sets on a daily timescale and less than 0.05 (or $5 \%$ ) on a monthly timescale in the altitude range $82-100 \mathrm{~km}$. Figure 5 presents the results for LER profiles $(\boldsymbol{y})$ and synthetic profiles based on the retrieved VER profiles averaged for a sample day (Fig. 5a) and a sample month (Fig. 5d). Figure 6 presents sample daily and monthly averaged VER profiles $(\boldsymbol{x})$ within the latitude range $20-25^{\circ} \mathrm{N}$.

The shape of the averaging kernel represented by a row of the matrix $\mathbf{A}=\mathbf{G K}$ is, in our case, a simple peak. The area of the averaging kernels is defined by

$a(z)=\int \mathbf{A}\left(z, z^{\prime}\right) \mathrm{d} z^{\prime}$,

where $z$ is the nominal altitude of the peak of the related averaging kernel. It characterizes the measurement response as a measure of the relative contribution of the observations and the a priori information to the retrieved VER profile (Rodgers, 2000). Figure 5 presents the averaging kernel rows (colored lines) and the measurement response (red dashed line) for a sample day (Fig. 5b) and a sample month (Fig. 5e) for the $20-25^{\circ} \mathrm{N}$ latitude range. The area of the averaging kernels - characterizing the measurement response - is close to 1 within the altitude range from 86 to $122 \mathrm{~km}$ with some deviations at the edges of this altitude range.

The vertical resolution of the retrieved VER profiles (usually defined as the "width" of the averaging kernels) was evaluated using the Backus-Gilbert spread $r(z)$ that characterizes the prevalence of useful information against noise at the geometric altitude $z$ (Rodgers, 1990):

$r(z)=\frac{12}{a(z)^{2}} \int\left(z-z^{\prime}\right)^{2} \mathbf{A}\left(z, z^{\prime}\right)^{2} \mathrm{~d} z^{\prime}$.

Figure 5 shows the vertical resolution according to BackusGilbert spread for a sample day (Fig. 5c) and a sample month (Fig. 5f) within the latitude range $20-25^{\circ} \mathrm{N}$. The approximately $3.7 \mathrm{~km}$ vertical resolution of the retrieved VER profiles is slightly coarser than the vertical sampling of the measured LER profiles of approximately $3.3 \mathrm{~km}$.

\subsection{Regularized total least squares minimization}

The automated RTLS procedure (Sima et al., 2004) was applied to determine the value of the regularization parameter $\gamma_{\mathrm{r}}$ (see Eq. 5).

Partial solutions $\boldsymbol{x}_{i}$ of the regularized problem are calculated as a function of a fixed $\gamma_{\mathrm{r}}$ :

$\boldsymbol{x}_{i}=\left(\mathbf{K}_{-i}^{\mathrm{T}} \mathbf{K}_{-i}+\gamma_{\mathrm{r}} \mathbf{H}^{\mathrm{T}} \mathbf{H}\right)^{-1} \mathbf{K}_{-i}^{\mathrm{T}} \boldsymbol{y}_{-i}=\mathbf{G}_{\mathrm{CV}} \boldsymbol{y}_{-i}$, 
where $\mathbf{K}_{-i}$ is the matrix $\mathbf{K}$ with rows $i$ set to zero, and $\boldsymbol{y}_{-i}$ is a measurement vector with elements $i$ set to zero (Sima et al., 2004). The fitting bias associated with ignoring parts of the data is measured on the basis of the calculated set of $\boldsymbol{x}_{i}\left(\gamma_{\mathrm{r}}\right)$ using the orthogonal distances composing the crossvalidation $(\mathrm{CV})$ function:

$\mathrm{CV}=\sum_{i=1}^{N} \frac{\left\|\mathbf{K}_{-i} \boldsymbol{x}_{i}-\boldsymbol{y}_{-i}\right\|^{2}}{\left\|\boldsymbol{x}_{i}\right\|^{2}+1}$,

where $\mathbf{G}_{\mathrm{CV}}$ is retrieval gain matrix corresponding to the $\mathrm{CV}$ function. The optimal $\gamma_{\mathrm{r}}$ is found at the minimum of the $\mathrm{CV}$ function (Sima et al., 2004). The RTLS algorithm was implemented with the LAPACK functions LUDC, LUSOL and LUMPROVE used in Interactive Data Language version 8.2 to solve the reduced inversion equation (see Eq. 2).

The range of possible regularization parameters was selected empirically to speed up the process of the $\gamma_{\mathrm{r}}$ calculation. The range not shaded with blue color in Fig. 7 represents the acceptable range of possible regularization parameters (in this figure the violet line corresponds to the $\mathrm{CV}$ function, the red line to the derivative of the $\mathrm{CV}$ function with respect to the index and the blue line to the regularization parameter function). Instabilities due to numerical random errors are present in the left part of the $\mathrm{CV}$ function curve where the value of the regularization parameter $\gamma_{\mathrm{r}}$ is too small and the retrieval is under-regularized (see the blueshaded zone on the left in Fig. 7). Small values of regularization parameters cause roughness of the curve representing the retrieved state vector $\boldsymbol{x}$. Too high values of the regularization parameter result in spikes of the inversion error curve corresponding to the scaled norm function $\left\|\mathbf{G}_{\mathrm{CV}}^{-1} \mathbf{G}_{\mathrm{CV}}-\mathbf{I}\right\|$ (see the black line in the blue-shaded zone on the right in Fig. 7). High values of regularization parameters mean that the retrieval is over-regularized leading to flatness of the retrieved state vector $\boldsymbol{x}$ curve.

The optimal $\gamma_{\mathrm{r}}$ is found automatically within the acceptable (not shaded) range. Within the acceptable range of $\gamma_{\mathrm{r}}$ the minimum of the $\mathrm{CV}$ function curve is identified to determine the optimal $\gamma_{\mathrm{r}}$. If the minimum of the $\mathrm{CV}$ function is located beyond the acceptable range, the steepest slope of the $\mathrm{CV}$ function is identified using the derivative of the $\mathrm{CV}$ function.

\subsection{Retrieval errors due to inversion}

The retrieval error is characterized by the total retrieval error $\mathbf{S}_{\text {tot }}$ (Rodgers, 2000) estimated for the retrieved VER profiles (see Eq. 3) as follows:

$\mathbf{S}_{\mathrm{tot}}=\mathbf{S}_{\mathrm{m}}+\mathbf{S}_{\mathrm{s}}+\mathbf{S}_{\mathrm{b}}+\mathbf{S}_{\mathrm{f}}$

with the measurement error covariance matrix $\mathbf{S}_{\mathrm{m}}$ related to random and systematic errors, the smoothing error covariance matrix $\mathbf{S}_{\mathrm{s}}$, the error covariance matrix $\mathbf{S}_{\mathrm{b}}$ related to random errors of model parameters that are not retrieved (see
Sects. 4 and 6) and the covariance matrix $\mathbf{S}_{\mathrm{f}}$ corresponding to the systematic forward model parameter error.

The covariance matrix $\mathbf{S}_{\mathrm{m}}$ due to retrieval system noise is given by

$\mathbf{S}_{\mathrm{m}}=\mathbf{G S}_{\mathrm{e}} \mathbf{G}^{\mathrm{T}}$

with the retrieval gain matrix $\mathbf{G}$ (see Eq. 3)

$\mathbf{G}=\mathbf{S}_{\mathrm{a}} \mathbf{K}^{\mathrm{T}}\left(\mathbf{K} \mathbf{S}_{\mathrm{a}} \mathbf{K}^{\mathrm{T}}+\mathbf{S}_{\mathrm{e}}+\gamma \mathbf{H}^{\mathrm{T}} \mathbf{H}\right)^{-1}$.

The covariance matrix $\mathbf{S}_{\mathrm{s}}$ due to smoothing error is given by

$\mathbf{S}_{\mathrm{S}}=(\mathbf{A}-\mathbf{I}) \mathbf{S}_{\mathrm{n}}(\mathbf{A}-\mathbf{I})^{\mathrm{T}}$,

with averaging kernel matrix $\mathbf{A}=\mathbf{G K}$, the identity matrix $\mathbf{I}$ and covariance matrix of the states' ensemble $\mathbf{S}_{\mathrm{n}}$ about the mean state $\overline{\boldsymbol{x}}$ (Rodgers, 2000): $\mathbf{S}_{\mathrm{n}}=\mathbf{E}\left[(\boldsymbol{x}-\overline{\boldsymbol{x}}) \cdot(\boldsymbol{x}-\overline{\boldsymbol{x}})^{\mathrm{T}}\right]$.

The diagonal matrix $\mathbf{S}_{\mathrm{b}}$ is the error covariance matrix containing the inverse and squared standard deviation (SD) of VER profiles with respect to uncertainties in the model parameters. The SD was found as the difference of the averaged VER profiles due to perturbations of $h^{\prime}$ representing the uncertainty in the tangent height determination $( \pm 500 \mathrm{~m}$, see Sect. 6.1). The covariance matrix $\mathbf{S}_{\mathrm{f}}$ due to forward model errors caused by approximations and imperfections of the forward model is given by

$\mathbf{S}_{\mathrm{f}}=\mathbf{G} \mathbf{K} \mathbf{S}_{\mathrm{b}} \mathbf{K}^{\mathrm{T}} \mathbf{G}^{\mathrm{T}}$.

\section{Retrieval of atomic oxygen concentration profiles}

The retrieval of atomic oxygen concentration profiles from the obtained green line VER profiles is based on the generally accepted two-step Barth transfer scheme and approximations derived from the measurements provided by the ETON rocket campaign (McDade et al., 1986). The $\mathrm{O}\left({ }^{1} \mathrm{~S}-{ }^{1} \mathrm{D}\right)$ SCIAMACHY nightglow green line emission spectra were processed according to the retrieval approach presented in Sect. 4 resulting in the retrieved VER profiles. The [O] retrieval is based on the well-known cubic equation (McDade et al., 1986), which represents the empirically derived relation between VER and [O] profiles; see Eq. (15).

The two-step Barth transfer scheme is represented by chemical reactions (see Reactions (1), (2) and the resulting Reaction (10) for the green line emission in Table 1) accompanied by quenching. The quenching of $\mathrm{O}_{2}^{*}$ as well as the quenching of $\mathrm{O}\left({ }^{1} \mathrm{~S}_{0}\right)$ by $\mathrm{O}_{2}$ was considered by McDade et al. (1986). In addition, Gobbi et al. (1992), Semenov (1997), Semenov and Shefov (2005) and Khomich et al. (2008) also considered quenching of $\mathrm{O}\left({ }^{1} \mathrm{~S}_{0}\right)$ by $\mathrm{O}\left({ }^{3} \mathrm{P}\right)$ or $\mathrm{N}_{2}$. The simplest of the [O] retrieval approaches based on the cubic equation does not account for the quenching of $\mathrm{O}\left({ }^{1} \mathrm{~S}_{0}\right)$ by $\mathrm{O}\left({ }^{3} \mathrm{P}\right)$ or $\mathrm{N}_{2}$, and the retrieved [O] profiles using this approach are 
Table 1. Photochemical reactions according to the two-step Barth transfer scheme (see Reactions (1), (2) and the resulting Reaction (10) for the green line emission) accompanied by quenching. The quantities listed in the column named intermediate coefficients correspond to the notation by Khomich et al. (2008) and the coefficients employed here (see Eq. 15) follow the notation by Gobbi et al. (1992) and McDade et al. (1986) and are listed in the column entitled used coefficients. See Sect. 5 for further details.

\begin{tabular}{clcc}
\hline $\begin{array}{c}\text { Item } \\
\#\end{array}$ & Chemical reaction & $\begin{array}{c}\text { Intermediate } \\
\text { coefficient }\end{array}$ & $\begin{array}{c}\text { Used } \\
\text { coefficient }\end{array}$ \\
\hline 1 & $\mathrm{O}\left({ }^{3} \mathrm{P}\right)+\mathrm{O}\left({ }^{3} \mathrm{P}\right)+\left(\mathrm{O}_{2}, \mathrm{~N}_{2}\right) \rightarrow \mathrm{O}_{2}^{*}+\left(\mathrm{O}_{2}, \mathrm{~N}_{2}\right)$ & $\alpha_{\mathrm{O}_{2}}$ & $\kappa_{1}$ \\
2 & $\mathrm{O}_{2}^{*}+\mathrm{O}\left({ }^{3} \mathrm{P}\right) \rightarrow \mathrm{O}_{2}+\mathrm{O}\left({ }^{1} \mathrm{~S}_{0}\right)$ & $\alpha_{\mathrm{O}}$ & $\mathrm{C}(1)$ \\
3 & $\mathrm{O}_{2}^{*}+\mathrm{O}\left({ }^{3} \mathrm{P}\right) \rightarrow \mathrm{O}_{2}+\mathrm{O}\left({ }^{3} \mathrm{P}\right)$ & $\beta_{\mathrm{O}}^{*}$ & \\
4 & $\mathrm{O}_{2}^{*}+\mathrm{N}_{2} \rightarrow \mathrm{O}_{2}+\mathrm{N}_{2}$ & $\beta_{\mathrm{N}_{2}}^{*}$ & $\mathrm{C}(2)$ \\
5 & $\mathrm{O}_{2}^{*}+\mathrm{O}_{2} \rightarrow \mathrm{O}_{2}+\mathrm{O}_{2}$ & $\beta_{\mathrm{O}_{2}}$ & \\
6 & $\mathrm{O}_{2}^{*} \rightarrow \mathrm{O}_{2}+h v$ & $A^{*}$ & $\mathrm{C}(0)$ \\
7 & $\mathrm{O}\left({ }^{1} \mathrm{~S}_{0}\right)+\mathrm{O}\left({ }^{3} \mathrm{P}\right) \rightarrow 2 \mathrm{O}\left({ }^{3} \mathrm{P},{ }^{1} \mathrm{D}_{2}\right)$ & $\beta_{\mathrm{O}}$ & ${ }_{\kappa}$ \\
8 & $\mathrm{O}\left({ }^{1} \mathrm{~S}_{0}\right)+\mathrm{N}_{2} \rightarrow \mathrm{O}\left({ }^{3} \mathrm{P},{ }^{1} \mathrm{D}_{2}\right)+\mathrm{N}_{2}^{*}$ & $\beta_{\mathrm{N}_{2}}$ & $2 \kappa_{5}$ \\
9 & $\mathrm{O}\left({ }^{1} \mathrm{~S}_{0}\right)+\mathrm{O}_{2} \rightarrow \mathrm{O}\left({ }^{3} \mathrm{P},{ }^{1} \mathrm{D}_{2}\right)+\mathrm{O}_{2}^{*}$ & $\beta_{\mathrm{O}_{2}}$ & ${ }^{3} \kappa_{5}$ \\
10 & $\mathrm{O}\left({ }^{1} \mathrm{~S}_{0}\right) \rightarrow \mathrm{O}\left({ }^{1} \mathrm{D}_{2}\right)+h v(\lambda=557.7 \mathrm{~nm})$ & $A_{558}$ & \\
11 & $\mathrm{O}\left({ }^{1} \mathrm{~S}_{0}\right) \rightarrow \mathrm{O}\left({ }^{3} \mathrm{P}_{1}\right)+h v(\lambda=297.2 \mathrm{~nm})$ & $A_{297}$ & $A_{1 \mathrm{~S}}$ \\
12 & $\mathrm{O}\left({ }^{1} \mathrm{~S}_{0}\right) \rightarrow \mathrm{O}\left({ }^{3} \mathrm{P}_{2}\right)+h v(\lambda=295.8 \mathrm{~nm})$ & $A_{296}$ & \\
\hline
\end{tabular}

Table 2. Einstein coefficients $\left(A_{558}, A_{1 S}\right)$, excitation parameters $(\mathrm{C}(0), \mathrm{C}(1), \mathrm{C}(2))$ and factors $\left(k_{1},{ }^{1} k_{5},{ }^{2} k_{5},{ }^{3} k_{5}\right)$ for rate coefficients $\left(\kappa_{1},{ }^{1} \kappa_{5},{ }^{2} \kappa_{5},{ }^{3} \kappa_{5}\right)$. The values are presented in the table according to their position in the Eq. (15) that gives the retrieved atomic oxygen concentration (see Table 1, Sect. 5 and Appendix for details).

\begin{tabular}{cccccccccc}
\hline [O] error bound & $A_{558}$ & $A_{1 \mathrm{~S}}$ & $\mathrm{C}(0)$ & $\mathrm{C}(1)$ & $\mathrm{C}(2)$ & $k_{1}$ & ${ }^{1} k_{5}$ & ${ }^{2} k_{5}$ & ${ }^{3} k_{5}$ \\
\hline-1 & $1.26 \mathrm{~s}^{-1}$ & $1.105 \mathrm{~s}^{-1}$ & 9 & 204 & 14 & 5.051 & 4.467 & 4.5 & 1.38 \\
0 & $1.16 \mathrm{~s}^{-1}$ & $1.228 \mathrm{~s}^{-1}$ & 13 & 224 & 17 & 4.700 & 5.000 & 5.0 & 2.32 \\
+1 & $1.06 \mathrm{~s}^{-1}$ & $1.350 \mathrm{~s}^{-1}$ & 17 & 244 & 20 & 4.349 & 5.533 & 5.5 & 3.26 \\
\hline
\end{tabular}

denoted as $\left[\mathrm{O}^{\text {cubic }}\right]$. The $[\mathrm{O}]$ retrieval approach based on the extended cubic equation accounts for the quenching of $\mathrm{O}\left({ }^{1} \mathrm{~S}\right)$ by $\mathrm{O}\left({ }^{3} \mathrm{P}\right)$ and $\mathrm{N}_{2}$, and the retrieved [O] profiles using such an approach are denoted as [ $\mathrm{O}^{\text {quench }}$ ].

According to the differences of these model approaches, the following equation based on the coefficients represented in Table 2 was used in the [O] retrieval:

$$
\begin{aligned}
\operatorname{VER} & =\kappa_{1}[\mathrm{O}]^{2}\left(\left[\mathrm{~N}_{2}\right]+\left[\mathrm{O}_{2}\right]\right) \cdot \frac{[\mathrm{O}]}{\left(\mathrm{C}(0)+\mathrm{C}(1)[\mathrm{O}]+\mathrm{C}(2)\left[\mathrm{O}_{2}\right]\right)} \\
& \cdot \frac{A_{558}}{\left(A_{1 \mathrm{~S}}+\sum_{i}\left({ }^{i} \kappa_{5}\left[M_{i}\right]\right)\right)},
\end{aligned}
$$

where $A_{558}\left(\mathrm{~s}^{-1}\right)$ is the transition probability of $\mathrm{O}\left({ }^{1} \mathrm{~S}-{ }^{1} \mathrm{D}\right)$, $A_{1 \mathrm{~S}}\left(\mathrm{~s}^{-1}\right)$ is the inverse radiative lifetime of $\mathrm{O}\left({ }^{1} \mathrm{~S}\right), \kappa_{1}$ $\left(\mathrm{cm}^{3} \mathrm{~s}^{-1}\right)$ is the rate coefficient for the three-body recombination of atomic oxygen and ${ }^{i} \kappa_{5}\left(\mathrm{~cm}^{3} \mathrm{~s}^{-1}\right)$ is the rate coefficient for quenching of $\mathrm{O}\left({ }^{1} \mathrm{~S}\right)$ by $M_{i}, i=1,2,3$. The dimensionless variables $\mathrm{C}(0), \mathrm{C}(1)$ and $\mathrm{C}(2)$ are the empirical $\mathrm{O}\left({ }^{1} \mathrm{~S}\right)$ excitation parameters; $\left[\mathrm{M}_{i}\right]=\left([\mathrm{O}],\left[\mathrm{N}_{2}\right],\left[\mathrm{O}_{2}\right]\right)$ represents concentrations of the respective species, $i=1,2,3$.

The first term on the right-hand side of the Eq. (15) describes rate of $\mathrm{O}_{2}^{*}$ production, the first and second terms describe the production of $\mathrm{O}\left({ }^{1} \mathrm{~S}\right)$ and all three terms on right- hand side describe the $\mathrm{O}\left({ }^{1} \mathrm{~S}-{ }^{1} \mathrm{D}\right)$ emission rate. Recombination of ground state atomic oxygen with rate $\kappa_{1}$ causes production of metastable oxygen $\mathrm{O}_{2}^{*}$. Subsequent deactivation of $\mathrm{O}_{2}^{*}$ by ground state $\mathrm{O}$ leads to $\mathrm{O}\left({ }^{1} \mathrm{~S}\right)$ production. Metastable molecular oxygen undergoes quenching described by parameters $\mathrm{C}(1), \mathrm{C}(2)$ and radiative relaxation described by radiative lifetime $\mathrm{C}(0)^{-1}$ so that the second term on the right-hand side of the Eq. (15) represents conversion to $\mathrm{O}\left({ }^{1} \mathrm{~S}\right)$. The influence of $\left[\mathrm{O}_{2}\right]$ and $\left[\mathrm{N}_{2}\right]$ was accounted for by the approximated parameters $\mathrm{C}(0), \mathrm{C}(1)$ and $\mathrm{C}(2)$ (McDade et al., 1986). The quenching of $\mathrm{O}\left({ }^{1} \mathrm{~S}\right)$ by $\mathrm{O}\left({ }^{3} \mathrm{P}\right)$ or $\mathrm{N}_{2}$ (described by Reactions (7) and (8) in Table 1 and introduced by Gobbi et al., 1992; Semenov, 1997; Semenov and Shefov, 2005; Khomich et al., 2008) is considered in the third term on the right-hand side of the Eq. (15).

The numerical approximation employed by Semenov (1997), Semenov and Shefov (2005) and Khomich et al. (2008) was applied to find the solution of Eq. (15) for ${ }^{i} \kappa_{5} \neq 0, i=1,2,3$ that corresponds to retrieving [ $\left.\mathrm{O}^{\text {quench }}\right]$ profiles. The atomic oxygen concentration [ $\left.\mathrm{O}^{\text {cubic }}\right]$ was retrieved as the exact solution of the cubic equation resulting from the Eq. (15) for ${ }^{1} \kappa_{5}={ }^{2} \kappa_{5}=0$. 
The discussed model approach for retrieving [O] profiles according to Eq. (15) requires parameters such as SCIAMACHY VER profiles, temperature-dependent rate coefficients $\kappa$ and atmospheric density $\left(\left[\mathrm{N}_{2}\right]+\left[\mathrm{O}_{2}\right]\right)$ profiles. Both $\left[\mathrm{O}^{\text {quench }}\right]$ and $\left[\mathrm{O}^{\text {cubic }}\right]$ retrievals were performed for all available sources of temperature and atmospheric density profiles.

In an ideal case, simultaneous measurements of all quantities required to calculate atomic oxygen profiles (i.e., temperature $(T),\left[\mathrm{N}_{2}\right],\left[\mathrm{O}_{2}\right]$ and VER profiles) are available. Unfortunately, such a data set is not available. So, in our case, the available SCIAMACHY VER profiles were combined with $T,\left[\mathrm{O}_{2}\right],\left[\mathrm{N}_{2}\right]$ profiles from NRLMSISE-00, SD-WACCM4 and SABER to calculate $\left[\mathrm{O}^{\text {quench }}\right]$ and $\left[\mathrm{O}^{\text {cubic }}\right]$ profiles according to Eq. (15). The presented retrievals $\left[\mathrm{O}^{\text {cubic }}\right]$ and $\left[\mathrm{O}^{\text {quench }}\right]$ are in the following discussion additionally denoted with lower indices showing the source of the $T,\left[\mathrm{O}_{2}\right]$ and $\left[\mathrm{N}_{2}\right]$ profile data as $\left[\mathrm{O}_{\mathrm{MSIS} 00}^{\text {cubic }}\right],\left[\mathrm{O}_{\mathrm{WACCM} 4}^{\text {cubic }}\right],\left[\mathrm{O}_{\mathrm{SABER}}^{\text {cubic }}\right]$ and $\left[\mathrm{O}_{\text {MSISO0 }}^{\text {quench }}\right],\left[\mathrm{O}_{\text {WACCM4 }}^{\text {quench }}\right],\left[\mathrm{O}_{\mathrm{SABER}}^{\text {quench }}\right]$. The retrieved $[\mathrm{O}]$ profiles were compared with atomic oxygen concentration profiles extracted from NRLMSISE-00, SD-WACCM4 and SABER denoted as $\left[\mathrm{O}^{\mathrm{MSIS} 00}\right],\left[\mathrm{O}^{\mathrm{WACCM} 4}\right]$ and $\left[\mathrm{O}^{\mathrm{SABER}}\right]$, respectively. Figures 10 and 11 show different possible sample daily and monthly averaged $[\mathrm{O}]$ profiles within the latitude range $20-25^{\circ} \mathrm{N}$.

\section{Error analysis}

The error analysis was done assuming independent contributions of uncertainty components to the maximum uncertainty of the retrieved data set, so correlations of the uncertainty components were neglected. The uncertainty components considered are assumed, first of all, to include random errors and systematic errors. The model parameters (that are not retrieved and related to random errors) correspond to the vector $\boldsymbol{b}$ (see Sect. 4). The components of the vector $\boldsymbol{b}$ are discussed at the relevant steps of the retrieval considering:

1. the error in the determination of the tangent height information affecting the VER retrieval (see Sect. 6.1)

2. the error in atmospheric density (represented by the sum of molecular oxygen $\left[\mathrm{O}_{2}\right]$ and nitrogen $\left[\mathrm{N}_{2}\right]$ concentrations) and temperature profiles affecting the $[\mathrm{O}]$ retrieval (see Sect. 6.2).

Successive additions of the uncertainty components to the solution were performed at each step of the retrieval. These steps result in (1) the spectral data set $\boldsymbol{P}$, (2) LER profiles, (3) VER profiles and (4) atomic oxygen concentration profiles. The error bounds (denoted by subscript \pm 1 ) were estimated in a way to avoid assumptions about the parameter distributions, e.g., that they are Gaussian.

At each step of the retrieval the relevant uncertainty components were accounted for (Kennedy et al., 2011) resulting in the unperturbed retrieval values $\left(\boldsymbol{P}_{0} \Rightarrow\right.$
$\left.\boldsymbol{L} \boldsymbol{E} \boldsymbol{R}_{0} \Rightarrow \boldsymbol{V} \boldsymbol{E} \boldsymbol{R}_{0} \Rightarrow[\boldsymbol{O}]_{0}\right)$ and their upper and lower bounds $\left(\boldsymbol{P}_{+1} \Rightarrow \boldsymbol{L} \boldsymbol{E} \boldsymbol{R}_{+1} \Rightarrow \boldsymbol{V} \boldsymbol{E} \boldsymbol{R}_{+1} \Rightarrow[\boldsymbol{O}]_{+1}\right.$ and $\boldsymbol{P}_{-1} \Rightarrow$ $\left.\boldsymbol{L} \boldsymbol{E} \boldsymbol{R}_{-1} \Rightarrow \boldsymbol{V} \boldsymbol{E} \boldsymbol{R}_{-1} \Rightarrow[\boldsymbol{O}]_{-1}\right)$. The uncertainty components considered at a given step of the retrieval were taken into account for the error bounds at the next step of the retrieval.

\subsection{Error analysis for the retrieval of volume emission rate profiles}

The maximum tangent height $(h)$ error of the SCIAMACHY limb measurements is assumed to be $\pm 500 \mathrm{~m}\left(h^{\prime}=500 \mathrm{~m}\right)$ (von Savigny et al., 2009). Modeled in a discrete mode (by applying $\pm h^{\prime}$ ), perturbations of $h$ were considered to resemble the random error of the determination of the tangent height. The uncertainty of the measured spectrum $\boldsymbol{P}$ is composed of two additive altitude-dependent components caused by variations of $h$ (related to a random error vector $\sigma_{h}$ ) and radiometric accuracy (related to a systematic error vector $\boldsymbol{\sigma}_{a}$ ). The altitude-dependent vector of SDs $\boldsymbol{\sigma}_{h}$ was calculated using spectra $\boldsymbol{P}$ and perturbed spectra denoted as $\boldsymbol{P}^{\text {temp }}: \boldsymbol{\sigma}_{h}^{+}=\left|\boldsymbol{P}^{\text {temp }}\left(+h^{\prime}\right)-\boldsymbol{P}\right|$ and $\boldsymbol{\sigma}_{h}^{-}=\left|\boldsymbol{P}-\boldsymbol{P}^{\text {temp }}\left(-h^{\prime}\right)\right|$.

A radiometric accuracy of the SCIAMACHY spectral measurements of $4 \%(a=4 \%)$ (Noël et al., 1998) was assumed to calculate the altitude-dependent vector of SDs $\sigma_{a}$ of the averaged spectra: $\boldsymbol{\sigma}_{a}^{+}=\left|\boldsymbol{P}^{\text {temp }}(+a)-\boldsymbol{P}\right|$ and $\boldsymbol{\sigma}_{a}^{-}=$ $\left|\boldsymbol{P}-\boldsymbol{P}^{\text {temp }}(-a)\right|$. Subtracting $\left(\boldsymbol{\sigma}_{a}^{-}+\boldsymbol{\sigma}_{h}^{-}\right)$from $\boldsymbol{P}$ yields the lower bound of the \pm 1 error bar of spectral data; its upper bound $\boldsymbol{P}_{+1}$ is calculated as $\boldsymbol{P}_{+1}=\boldsymbol{P}+\left(\boldsymbol{\sigma}_{a}^{+}+\boldsymbol{\sigma}_{h}^{+}\right)$. The unchanged retrieval spectrum $\boldsymbol{P}_{0}$ is equal to $\boldsymbol{P}$. Figure 3 presents sample daily (Fig. 3a) and monthly (Fig. 3b) averaged green line spectra at the altitude of $95 \mathrm{~km}$ within the latitude range $20-25^{\circ} \mathrm{N}$.

Each spectral data set $\left(\boldsymbol{P}_{-1}, \boldsymbol{P}_{0}\right.$ and $\left.\boldsymbol{P}_{+1}\right)$ was processed (see Sect. 3) separately to calculate the corresponding LER profiles denoted by upper index temp: $\boldsymbol{L} \boldsymbol{E} \boldsymbol{R}_{-1}^{\text {temp }}$, $\boldsymbol{L} \boldsymbol{E} \boldsymbol{R}_{0}^{\text {temp }}$ and $\boldsymbol{L} \boldsymbol{E} \boldsymbol{R}_{+1}^{\text {temp }}$. The emission-free spectral intervals (see Sect. 3) of $\boldsymbol{P}_{0}$ were used to calculate the uncertainty component (related to the random error vector $\sigma_{l}$ ) of the LER when integrating over the green line spectral interval. The altitude-dependent vector of SDs $\boldsymbol{\sigma}_{l}$ of $\boldsymbol{L} \boldsymbol{E} \boldsymbol{R}_{0}$ was subtracted from $\boldsymbol{L} \boldsymbol{E} \boldsymbol{R}_{-1}^{\text {temp }}$, which resulted in the lower error bound $\boldsymbol{L} \boldsymbol{E} \boldsymbol{R}_{-1}$. The upper bound is $\boldsymbol{L} \boldsymbol{E} \boldsymbol{R}_{+1}=\boldsymbol{L} \boldsymbol{E} \boldsymbol{R}_{+1}^{\text {temp }}+\boldsymbol{\sigma}_{l}$. The unchanged LER profile $\boldsymbol{L} \boldsymbol{E} \boldsymbol{R}_{0}$ is equal to $\boldsymbol{L} \boldsymbol{E} \boldsymbol{R}_{0}^{\text {temp }}$. Figure 4 presents sample daily (Fig. 4a) and monthly (Fig. 4b) averaged LER profiles within the latitude range $20-25^{\circ} \mathrm{N}$ with calculated uncertainty components.

The inversion scheme described above and supported by RTLS was applied to $\boldsymbol{L} \boldsymbol{E} \boldsymbol{R}_{-1}, \boldsymbol{L} \boldsymbol{E} \boldsymbol{R}_{0}$ and $\boldsymbol{L} \boldsymbol{E} \boldsymbol{R}_{+1}$ to calculate VER profiles denoted with the upper index temp: $\boldsymbol{V} \boldsymbol{E} \boldsymbol{R}_{-1}^{\text {temp }}, \boldsymbol{V} \boldsymbol{E} \boldsymbol{R}_{0}^{\text {temp }}$ and $\boldsymbol{V} \boldsymbol{E} \boldsymbol{R}_{+1}^{\text {temp }}$. From the diagonal elements of the error covariance matrix $\mathbf{S}_{\text {tot }}$ (see Eq. (10), Sect. 4.3) square roots were taken, resulting in the altitudedependent vector of SDs $\sigma_{\mathrm{S}_{\mathrm{tot}}}$. The uncertainties $\sigma_{\mathrm{S}_{\mathrm{tot}}}$ of 
$\boldsymbol{V} \boldsymbol{E} \boldsymbol{R}_{0}$ were subtracted from $\boldsymbol{V} \boldsymbol{E} \boldsymbol{R}_{-1}^{\text {temp }}$, resulting in the lower error bound $\boldsymbol{V} \boldsymbol{E} \boldsymbol{R}_{-1}$. The upper bound is $\boldsymbol{V} \boldsymbol{E} \boldsymbol{R}_{+1}=$ $\boldsymbol{V} \boldsymbol{E} \boldsymbol{R}_{+1}^{\text {temp }}+\sigma_{\mathrm{S}_{\mathrm{tot}}}$. The unchanged VER profile $\boldsymbol{V} \boldsymbol{E} \boldsymbol{R}_{0}$ is equal to $\boldsymbol{V} \boldsymbol{E} \boldsymbol{R}_{0}^{\text {temp }}$. Figure 6 presents sample daily (Fig. 6a) and monthly (Fig. 6b) averaged VER profiles within the latitude range $20-25^{\circ} \mathrm{N}$ with calculated uncertainty components of $\sigma_{\mathrm{S}_{\mathrm{tot}}}$.

\subsection{Error analysis for the retrieval of atomic oxygen concentration profiles}

The maximum and minimum values of photochemical parameters (see Eq. 15) were used to estimate the contribution of photochemical model errors to the error in retrieved [O] profiles. The ranges of coefficients and other parameters used in the photochemical model (see Eq. 15) to determine the \pm 1 error bar of the [O] profiles are presented in Table 2.

Each VER profile $\left(\boldsymbol{V} \boldsymbol{E} \boldsymbol{R}_{-1}, \boldsymbol{V} \boldsymbol{E} \boldsymbol{R}_{0}\right.$ and $\left.\boldsymbol{V} \boldsymbol{E} \boldsymbol{R}_{+1}\right)$ was processed (see Sect. 5) assuming that simultaneously varied photochemical parameters cause maximum uncertainty of [O] separately, yielding $[\mathrm{O}]$ profiles denoted with the upper index temperature: $[\boldsymbol{O}]_{-1}^{\text {temp }},[\boldsymbol{O}]_{0}^{\text {temp }}$ and $[\boldsymbol{O}]_{+1}^{\text {temp }}$.

Moreover, model parameters that affect the [O] retrieval, but are not retrieved, are considered at this step, i.e., temperature and the sum of molecular oxygen $\left[\mathrm{O}_{2}\right]$ and nitrogen $\left[\mathrm{N}_{2}\right]$ concentrations. To determine the influence of temperature and $\left[\mathrm{O}_{2}\right]+\left[\mathrm{N}_{2}\right]$ on the resulting random error, temperature was perturbed by $T^{\prime}=5 \mathrm{~K}$ and $\left[\mathrm{O}_{2}\right]+\left[\mathrm{N}_{2}\right]$ by $D^{\prime}=10 \%$. The altitude-dependent vector of SDs $\boldsymbol{\sigma}_{T}$ was determined as: $\boldsymbol{\sigma}_{T}^{+}=\left|\left[\boldsymbol{O}\left(+T^{\prime}\right)\right]_{0}^{\text {temp }}-[\boldsymbol{O}]_{0}^{\text {temp }}\right|$ and $\boldsymbol{\sigma}_{T}^{-}=\left|[\boldsymbol{O}]_{0}^{\text {temp }}-\left[\boldsymbol{O}\left(-T^{\prime}\right)\right]_{0}^{\text {temp }}\right|$. The altitude-dependent SDs $\sigma_{D}$ in perturbations of $D^{\prime}$ were calculated as follows: $\boldsymbol{\sigma}_{D}^{-}=\left|\left[\boldsymbol{O}\left(-D^{\prime}\right)\right]_{0}^{\text {temp }}-[\boldsymbol{O}]_{0}^{\text {temp }}\right|$ and $\boldsymbol{\sigma}_{D}^{+}=\mid[\boldsymbol{O}]_{0}^{\text {temp }}-$ $\left[\boldsymbol{O}\left(+D^{\prime}\right)\right]_{0}^{\text {temp }} \mid$. The cumulative uncertainties due to perturbations in $T^{\prime}$ and $D^{\prime}$ contribute simultaneously to the \pm 1 error bar of [O] causing maximum uncertainty: $\sigma_{T D}^{+}=\sigma_{T}^{+}+$ $\boldsymbol{\sigma}_{D}^{-}$and $\boldsymbol{\sigma}_{T D}^{-}=\boldsymbol{\sigma}_{T}^{-}+\boldsymbol{\sigma}_{D}^{+}$.

The uncertainties $\boldsymbol{\sigma}_{T D}^{-}$of $[\boldsymbol{O}]_{0}^{\text {temp }}$ were subtracted from $[\boldsymbol{O}]_{-1}^{\text {temp }}$, resulting in the lower error bound $[\boldsymbol{O}]_{-1}$. The upper bound is $[\boldsymbol{O}]_{+1}=[\boldsymbol{O}]_{+1}^{\text {temp }}+\boldsymbol{\sigma}_{T D}^{+}$. The unchanged $[\mathrm{O}]$ profile $[\boldsymbol{O}]_{0}$ is equal to $[\boldsymbol{O}]_{0}^{\text {temp }}$. Figure 8 shows sample daily and monthly averaged atomic oxygen concentration ([O $\left.\left.\mathrm{O}_{\mathrm{SABER}}^{\text {quench }}\right]\right)$ profiles within the latitude range $20-25^{\circ} \mathrm{N}$.

\section{Results and discussion}

In this section we first present results of the error analysis introduced in Sect. 6. Then the derived [O] densities are assessed via comparisons with NRLMSISE-00 and SDWACCM4 model results as well as with TIMED/SABER retrievals. The verification of the $[\mathrm{O}]$ retrieval compares retrieved with reference $[\mathrm{O}]$ profiles and ideally allows a wellfounded choice between the cubic and the extended cubic

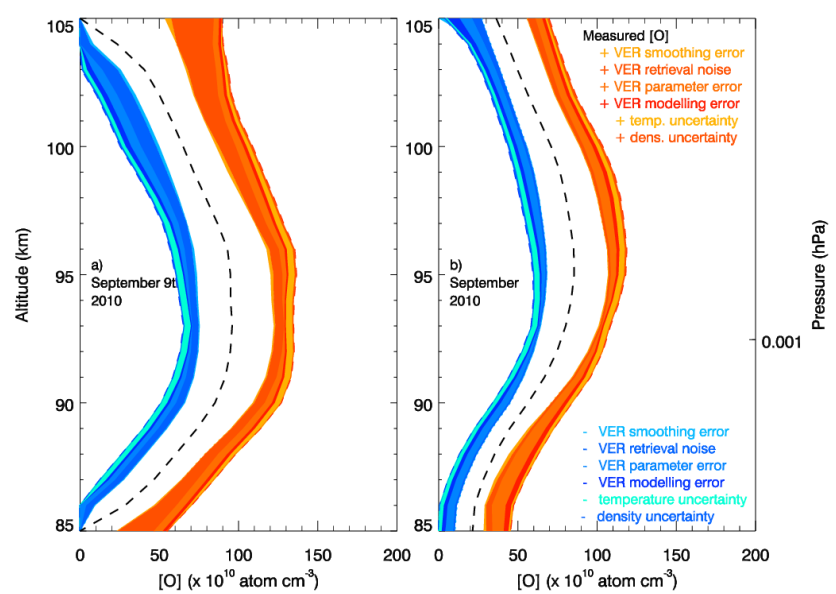

Figure 8. Sample daily (a) and monthly (b) averaged atomic oxygen concentration ( $\left.\left[\mathrm{O}_{\mathrm{SABER}}^{\text {quench }}\right]\right)$ profiles for the $20-25^{\circ} \mathrm{N}$ latitude range with uncertainty components $\sigma_{\mathbf{S}_{\mathrm{s}}}$ (yellow), $\sigma_{\mathbf{S}_{\mathrm{m}}}$ (light red), $\sigma_{\mathbf{S}_{\mathrm{b}}}$ (orange), $\sigma_{\mathbf{S}_{\mathrm{f}}}$ (red) introduced for retrieving $\boldsymbol{V} \boldsymbol{E} \boldsymbol{R}_{+1}$ and propagated to $[\boldsymbol{O}]_{+1}$, while $\boldsymbol{\sigma}_{T D}^{+}$(light yellow and dark orange marked components) is calculated directly for the determination of $[\boldsymbol{O}]_{+1}$. Similarly, $\sigma_{\mathbf{S}_{\mathrm{s}}}$ (cyan), $\sigma_{\mathbf{S}_{\mathrm{m}}}$ (light blue), $\sigma_{\mathbf{S}_{\mathrm{b}}}$ (dark cyan) and $\sigma_{\mathbf{S}_{\mathrm{f}}}$ (blue) are introduced for calculating $\boldsymbol{V} \boldsymbol{E} \boldsymbol{R}_{-1}$ and are propagated to $[\boldsymbol{O}]_{-1}$, while $\boldsymbol{\sigma}_{T D}^{-}$(light cyan and dark cyan marked components) is directly calculated when determining $[\boldsymbol{O}]_{-1}$. See Sects. 5, 6.2 and 7.1 for further details.

equations and a selection of the most appropriate source of temperature and density profiles from the different available sources. The verification was carried out in several steps including comparisons of reference and retrieved $[\mathrm{O}]$ profiles for

1. sample profiles (see Sect. 7.2)

2. climatologies of relative differences (see Sect. 7.3)

3. climatologies of correlation coefficients (see Sect. 7.4).

In Sect. 7.5 we present first results of seasonal [O] variations in the SCIAMACHY and the reference data sets and of the complete SCIAMACHY [O] data set covering the period from August 2002 to April 2012.

\subsection{Results of error analysis}

The calculated uncertainty components in the retrieved VER profiles are represented by $\boldsymbol{V} \boldsymbol{E} \boldsymbol{R}_{+1}$ and $\boldsymbol{V} \boldsymbol{E} \boldsymbol{R}_{-1}$ in Fig. 6 with daily (Fig. 6a) and monthly (Fig. 6b) averaging within the latitude range $20-25^{\circ} \mathrm{N}$. The distribution of uncertainty components of the retrieved [O] profiles is presented in Fig. 8 with daily (Fig. 8a) and monthly (Fig. 8b) averaging within the same latitude range. The magnitudes of the errors, which are typical of the entire data set, are listed in Tables 38 in the supplementary material. The estimated magnitude of the maximum error (up to $60 \%$ on the daily timescale and up to $47 \%$ on the monthly timescale in the altitude 

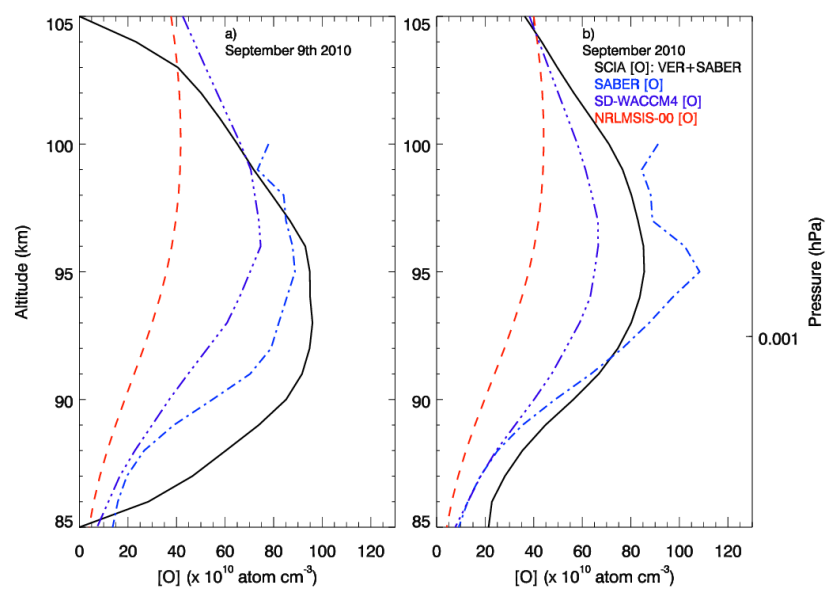

Figure 9. Sample daily (a) and monthly (b) averaged atomic oxygen concentration profiles (black solid $\left[\mathrm{O}_{\mathrm{SABER}}^{\text {quench }}\right]$ ) compared with profiles measured by SABER (blue dash dot $\left[\mathrm{O}^{\mathrm{SABER}}\right]$ ) and modeled with SD-WACCM4 (violet dash dot dot dot $\left[\mathrm{O}^{\mathrm{WACCM} 4}\right]$ ) and NRLMSISE-00 (red dashed $\left[\mathrm{O}^{\mathrm{MSIS} 00}\right]$ ) for the $20-25^{\circ} \mathrm{N}$ latitude range and at local times between 21:00 and 23:00.

range $90-100 \mathrm{~km}$; see the last two columns of Tables 3-8) is bigger than the magnitude of the root-sum-square (RSS) error for other satellite derivations of [O] (less than $25 \%$ for SABER (Mlynczak et al., 2013) and less than $44 \%$ for OSIRIS (Sheese et al., 2011)). Note that the maximum error can be equal to the RSS error if all absolute error components are equal, otherwise the estimation of maximum uncertainty results in a bigger error than an RSS error.

The averaged errors in the altitude range $90-100 \mathrm{~km}$ were used to calculate the relative errors of each error component to the total error so that added partial errors result in $100 \%$ of the error (see the last two columns of Tables 3-8). The retrieval noise $\sigma_{S_{\mathrm{m}}}$ component is represented by relatively large colored zones in Fig. 6 and in Fig. 8 and corresponds to 54 and $37 \%$ partial error, respectively. The corresponding colored zone is smaller in the monthly averaged profiles (21 and $12 \%$ ) because of a larger number of averaged profiles. The modeling error $\sigma_{\mathbf{S}_{\mathrm{f}}}$ in VER and [O] profiles is relatively small (12 and $9 \%$ on the daily timescale as well as 24 and $16 \%$ on the monthly timescale, respectively) compared to the total uncertainty $\sigma_{\mathbf{S}_{\text {tot }}}(100 \%)$ associated with the inversion procedure.

The $[\mathrm{O}]$ profile error associated with temperature errors assumes the highest values within the altitude range where the $[\mathrm{O}]$ peak occurs. Similar behavior, but to a lesser extent, is characteristic for the $[\mathrm{O}]$ profile uncertainty caused by errors in atmospheric density (the sum of $\left[\mathrm{O}_{2}\right]$ and $\left[\mathrm{N}_{2}\right]$ ).

\subsection{Verification step 1}

Figure 9 shows atomic oxygen concentration $\left(\left[\mathrm{O}_{\mathrm{SABER}}^{\text {quench }}\right]\right)$ profiles and reference [O] profiles provided by SABER,

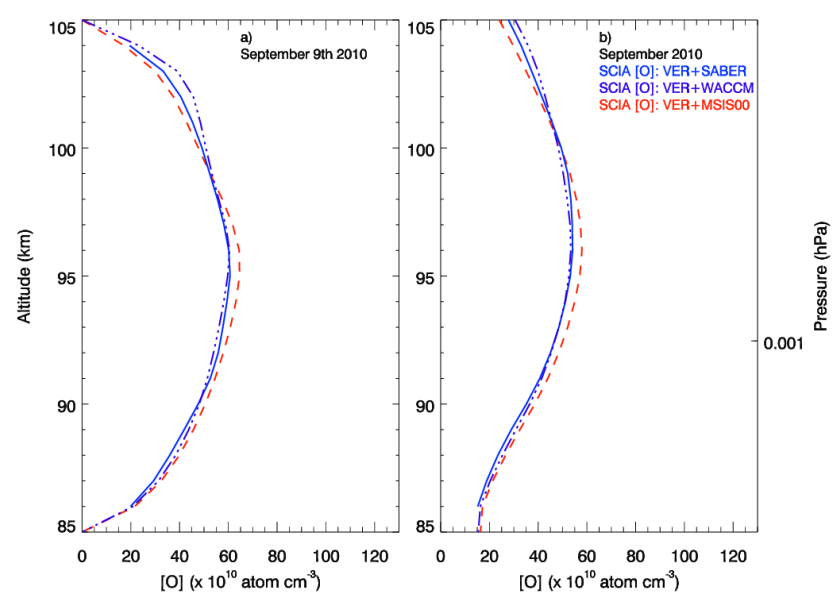

Figure 10. Sample daily (a) and monthly (b) averaged atomic oxygen concentration profiles $\left(\left[\mathrm{O}_{\mathrm{SABER}}^{\text {cubic }}\right]-\right.$ blue solid, $\left[\mathrm{O}_{\mathrm{WACCM} 4}^{\text {cubic }}\right]-$ violet dash-dotted, [O $\mathrm{O}_{\text {MSISO0 }}^{\text {cubic }}$ - red dashed) according to the cubic equation (McDade et al., 1986) for different sources of background atmospheric profiles and for the $20-25^{\circ} \mathrm{N}$ latitude range.
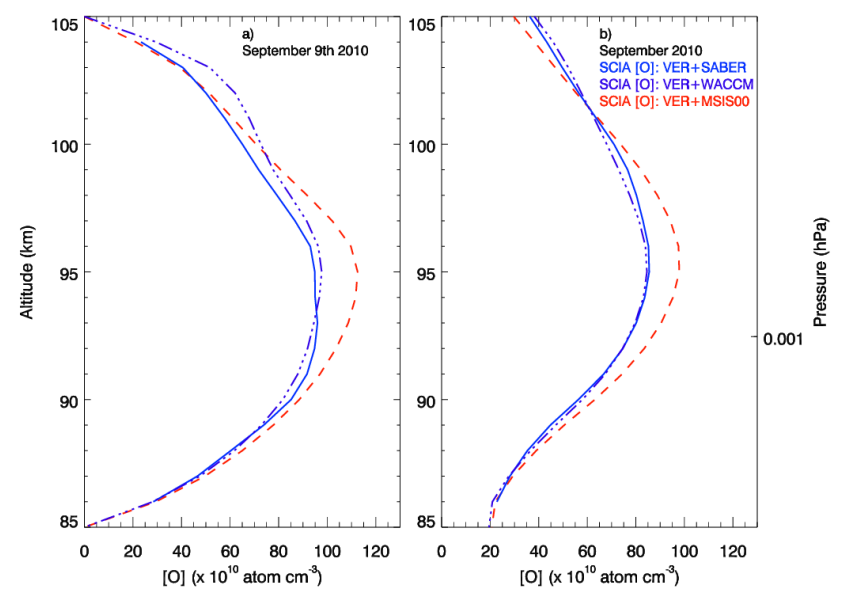

Figure 11. Sample daily (a) and monthly (b) averaged atomic oxygen concentration profiles $\left(\left[\mathrm{O}_{\mathrm{SABER}}^{\text {quench }}\right]-\right.$ blue solid, $\left[\mathrm{O}_{\mathrm{WACCM} 4}^{\text {quench }}\right]-$ violet dash-dotted, $\left[\mathrm{O}_{\mathrm{MSIS} 00}^{\text {quench }}\right]$ - red dashed) according to the extended cubic equation by Gobbi et al. (1992) and Khomich et al. (2008) for different sources of background atmospheric profiles and for the $20-25^{\circ} \mathrm{N}$ latitude range.

NRLMSISE-00 and SD-WACCM4 in the altitude range $85-105 \mathrm{~km}$ in the latitude bin $20-25^{\circ} \mathrm{N}$ for a sample day (9 September 2010) and month (September 2010). The altitude dependence of $\left[\mathrm{O}_{\mathrm{SABER}}^{\text {quench }}\right]$ in comparison with $\left[\mathrm{O}^{\mathrm{SABER}}\right]$, $\left[\mathrm{O}^{\mathrm{MSIS} 00}\right]$ and $\left[\mathrm{O}^{\mathrm{WACCM} 4}\right]$ exhibits some deviations in the altitude range $85-87 \mathrm{~km}$. These deviations correspond to low values of the measurement response (see Fig. 5) in the altitude range $82-87 \mathrm{~km}$. The comparisons shown in Fig. 9 allow the preliminary conclusion that SABER as the source of temperature and density profiles (which we need to retrieve 

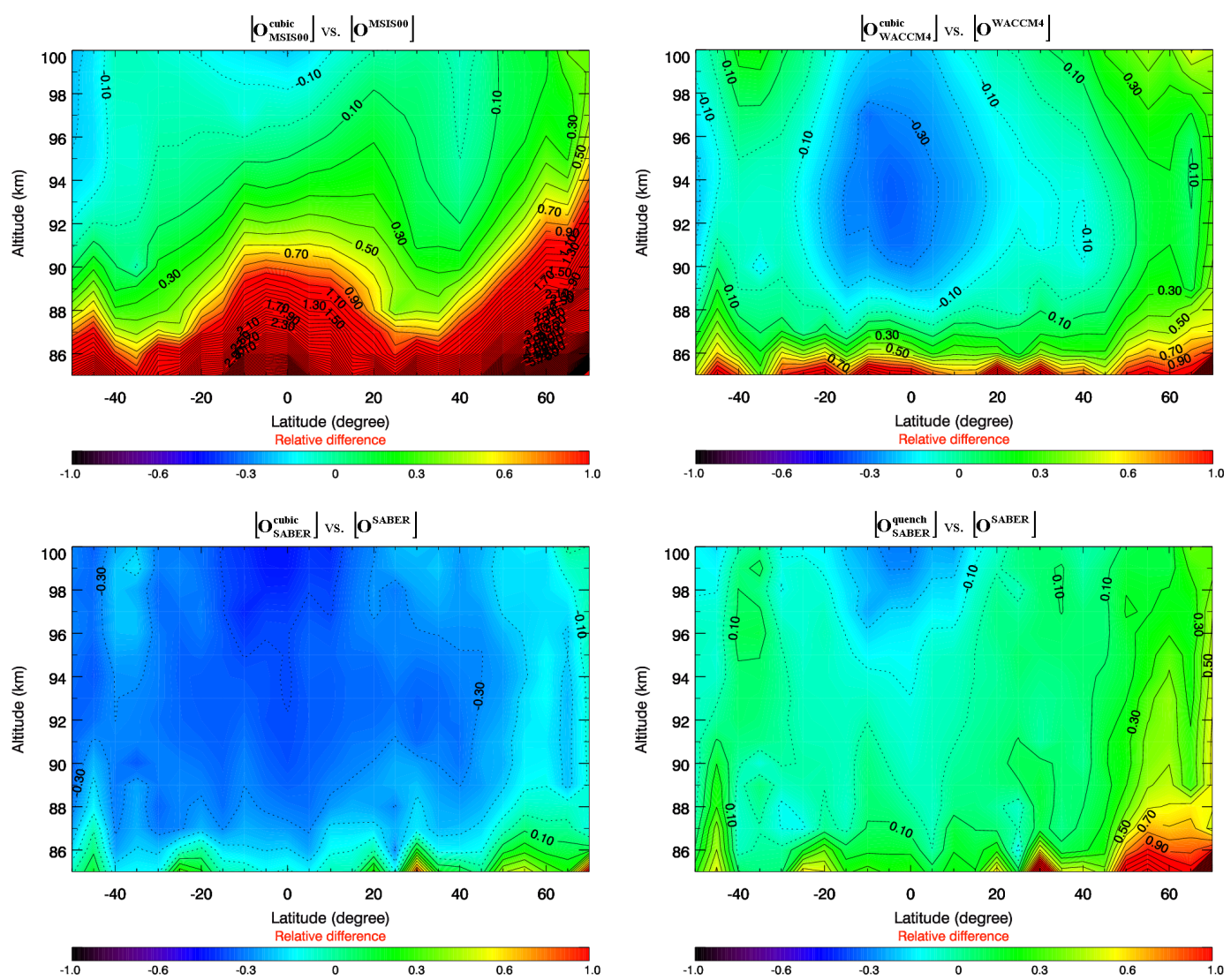

Figure 12. Relative differences in monthly averaged atomic oxygen fields from April 2010 to March 2011: [O $\mathrm{O}_{\mathrm{MSIS} 00}^{\text {cubic }}$ ] compared with reference $\left[\mathrm{O}^{\mathrm{MSIS} 00}\right]$ (top left), $\left[\mathrm{O}_{\text {WACCM4 }}^{\text {cubic }}\right]$ compared with reference $\left[\mathrm{O}^{\mathrm{WACCM} 4}\right]$ (top right), $\left[\mathrm{O}_{\mathrm{SABER}}^{\text {cubic }}\right]$ compared with reference $\left[\mathrm{O}^{\mathrm{SABER}}\right]$ (bottom left) and $\left[\mathrm{O}_{\mathrm{SABER}}^{\text {quench }}\right]$ compared with reference $\left[\mathrm{O}^{\mathrm{SABER}}\right]$ (bottom right).

[O] profiles from SCIAMACHY VER profiles) seems to be preferable.

Figure 9 allows the conclusion to be drawn that the reference $\left[\mathrm{O}^{\mathrm{MSISO0}}\right]$ profiles are characterized by lower concentrations in comparison with the retrieved $\left[\mathrm{O}_{\mathrm{SABER}}^{\text {quench }}\right]$ profiles. We use the absolute of the mean relative difference $(<|\epsilon|>)$ determined according to the equation $<|\epsilon|>=<$ $\left|\left([\mathrm{O}]^{\text {current }}-[\mathrm{O}]^{\text {reference }}\right) /[\mathrm{O}]^{\text {reference }}\right|>$ averaged over the altitude range $90-100 \mathrm{~km}$ to quantify differences between different $[\mathrm{O}]$ profiles. For $\left[\mathrm{O}^{\mathrm{MSISO0}}\right]\left(\left[\mathrm{O}^{\text {current }}\right]\right)$ in comparison with $\left[\mathrm{O}_{\mathrm{SABER}}^{\text {quench }}\right]\left(\left[\mathrm{O}^{\text {reference }}\right]\right)$ we obtain $<|\epsilon|>\approx$ 0.6 on the daily timescale and $\approx 0.54$ on the monthly timescale. For $\left[\mathrm{O}^{\text {WACCM4 }}\right]$ in comparison with $\left[\mathrm{O}_{\mathrm{SABER}}^{\text {quench }}\right]$ we obtain $\langle|\epsilon|>\approx 0.27$ on the daily timescale and $\approx 0.24$ on the monthly timescale. For $\left[\mathrm{O}^{\mathrm{SABER}}\right]$ in comparison with $\left[\mathrm{O}_{\mathrm{SABER}}^{\text {quench }}\right]$ we obtain $\langle|\epsilon|>\approx 0.13$ on the daily timescale and $\approx 0.14$ on the monthly timescale.

Figures 10 and 11 (with data corresponding to the same altitude, latitude and time ranges as in Fig. 9) present [O] profiles retrieved from SCIAMACHY VER profiles according to the cubic $\left(\left[\mathrm{O}^{\text {cubic }}\right]\right)$ and extended cubic ([$\left.\left.{ }^{\text {quench }}\right]\right)$ approaches (see Eq. 15) and show that $\left[\mathrm{O}^{\text {quench }}\right]$ concentrations are higher than the $\left[\mathrm{O}^{\text {cubic }}\right]$ concentrations. $\langle|\epsilon|>$ for $\left[\mathrm{O}_{\mathrm{WACCM} 4}^{\text {cubic }}\right]$ in comparison with $\left[\mathrm{O}_{\mathrm{SABER}}^{\text {cubic }}\right]$ is about 0.02 on the daily and monthly timescale. $\left\langle|\epsilon|>\right.$ for $\left[\mathrm{O}_{\text {MSIS } 00}^{\text {cubic }}\right]$ in comparison with $\left[\mathrm{O}_{\mathrm{SABER}}^{\text {cubic }}\right]$ is about 0.05 on the daily timescale and 0.06 on the monthly timescale. $\langle|\epsilon|>$ for $\left[\mathrm{O}_{\text {WACCM4 } 4}^{\text {quench }}\right]$ in comparison with $\left[\mathrm{O}_{\mathrm{SABER}}^{\text {quench }}\right]$ is about 0.05 on the daily timescale and 0.02 on the monthly timescale. $<|\epsilon|>$ for $\left[\mathrm{O}_{\mathrm{MSISO0}}^{\text {quench }}\right]$ in comparison with $\left[\mathrm{O}_{\mathrm{SABER}}^{\text {quench }}\right]$ is about 0.13 on the daily timescale and 0.11 on the monthly timescale. This leads to the preliminary conclusion that NRLMSISE-00 does not seem to be a reliable source of temperature and density profiles. A comparison between Figs. 9, 10 and 11 indicates that $\left[\mathrm{O}_{\mathrm{SABER}}^{\text {quench }}\right]$ profiles are (by sight) in better agreement with $\left[\mathrm{O}^{\mathrm{SABER}}\right]$ profiles than $\left[\mathrm{O}^{\text {cubic }}\right]$ profiles are. This implies that the extended cubic equation seems to be preferable for the retrieval of $[\mathrm{O}]$ profiles.

\subsection{Verification step 2}

Relative differences $(\epsilon)$ between different [O] profiles were calculated according to the equation $\epsilon=\left([\mathrm{O}]^{\text {current }}\right.$ 

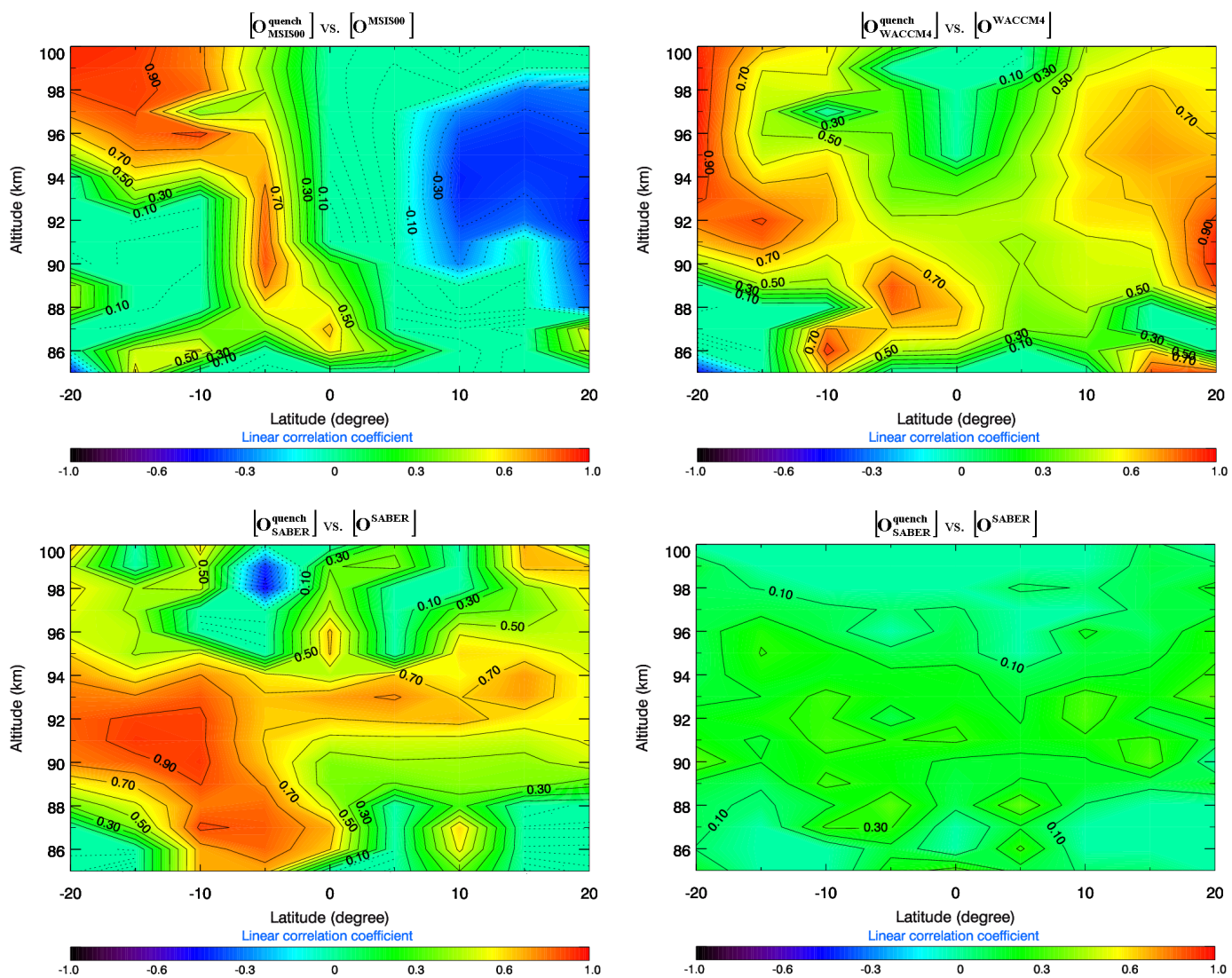

Figure 13. Correlation coefficients for atomic oxygen fields from April 2010 to March 2011: monthly averaged [O $\mathrm{O}_{\mathrm{MSIS} 00}^{\text {quench }}$ cross-correlated with $\left[\mathrm{O}^{\mathrm{MSIS00}}\right]$ (top left), monthly averaged $\left[\mathrm{O}_{\mathrm{WACCM} 4}^{\text {quench }}\right]$ cross-correlated with $\left[\mathrm{O}^{\text {WACCM4 }}\right]$ (top right), monthly averaged [O $\left.{ }_{\mathrm{SABER}}^{\text {quench }}\right]$ crosscorrelated with $\left[\mathrm{O}^{\mathrm{SABER}}\right]$ (bottom left) and daily averaged $\left[\mathrm{O}_{\mathrm{SABER}}^{\text {quench }}\right]$ cross-correlated with $\left[\mathrm{O}^{\mathrm{SABER}}\right]$ (bottom right).

$\left.[\mathrm{O}]^{\text {reference }}\right) /[\mathrm{O}]^{\text {reference }}$. Figure 12 presents sample distributions of relative $[\mathrm{O}]$ differences as a function of latitude and altitude in the time period from April 2010 to March 2011 which corresponds to SD-WACCM4 data that we had at our disposal.

Provided that $\langle|\epsilon|>$ in the following text is averaged over altitude range $86-100 \mathrm{~km}$, the latitude range $50^{\circ} \mathrm{S}-$ $70^{\circ} \mathrm{N}$ and the time period from April 2010 to March 2011, we find that $\left\langle|\epsilon|>\right.$ for [O $\left.\mathrm{O}_{\text {MSIS00 }}^{\text {cubic }}\right]$ ([O $\left.{ }^{\text {current }}\right]$ ) in comparison with $\left[\mathrm{O}^{\mathrm{MSISO0}}\right]$ ([O $\left.\left.\mathrm{O}^{\text {reference }}\right]\right)$ is about 0.81 on the monthly timescale. The mean absolute relative difference between $\left[\mathrm{O}_{\text {MSIS00 }}^{\text {quench }}\right]$ and $\left[\mathrm{O}^{\mathrm{MSIS00}}\right]$ (not shown in Fig. 12) of $\langle|\epsilon|>\approx$ 1.74 is at least twice as large as the value for [O $\left.\mathrm{O}_{\text {MSIS } 00}^{\text {cubic }}\right]$ vs. $\left[\mathrm{O}^{\mathrm{MSIS} 00}\right]$. The mean absolute relative difference between $\left[\mathrm{O}_{\mathrm{WACCM} 4}^{\text {quench }}\right]$ and $\left[\mathrm{O}^{\mathrm{WACCM} 4}\right]$ (not shown in Fig. 12) is $\approx$ 0.65. $\left\langle|\epsilon|>\right.$ for $\left[\mathrm{O}_{\text {WACCM }}^{\text {cubic }}\right]$ in comparison with $\left[\mathrm{O}^{\mathrm{WACCM} 4}\right]$ is about 0.24 and exhibits the same anomaly cluster with high negative $\langle|\epsilon|>$ of unknown origin in the subtropical region as for $\left[\mathrm{O}_{\mathrm{WACCM} 4}^{\text {quench }}\right]$ vs. $\left[\mathrm{O}^{\mathrm{WACCM} 4}\right]$. For $\left[\mathrm{O}_{\mathrm{SABER}}^{\text {quench }}\right]$ in comparison with $\left[\mathrm{O}^{\mathrm{SABER}}\right]$ we obtain $\langle|\epsilon|>\approx 0.19$, which is smaller than $\left\langle|\epsilon|>\right.$ for $\left[\mathrm{O}_{\mathrm{SABER}}^{\text {cubic }}\right]$ vs. [O $\left.\mathrm{O}^{\text {SABER }}\right]$ of about 0.28 . This enables the preliminary conclusion that NRLMSISE-00 is not an adequate source of [O] profiles. We use SABER temperature and density profiles for future analysis and the extended cubic approach to retrieve [O] profiles.

We now briefly discuss differences between the $\mathrm{O}$ retrievals from SCIAMACHY O green line observations derived in this study with similar retrievals - also from SCIAMACHY O green line measurements - recently presented by Kaufmann et al. (2014). Kaufmann et al. (2014) also compared their retrievals to co-located SABER measurements and found an approximately $30 \%$ low bias compared to SABER atomic oxygen. Since the photochemical model employed by Kaufmann et al. (2014) is essentially the one by McDade et al. (1986) - corresponding to our $\left[\mathrm{O}_{\mathrm{SABER}}^{\text {cubic }}\right]$ data set (see lower left panel of Fig. 12) - we come to a similar conclusion as Kaufmann et al. (2014): our SCIAMACHY $\left[\mathrm{O}_{\mathrm{SABER}}^{\text {cubic }}\right]$ retrievals are at least $30 \%$ lower in comparison with $\left[\mathrm{O}^{\mathrm{SABER}}\right]$. 

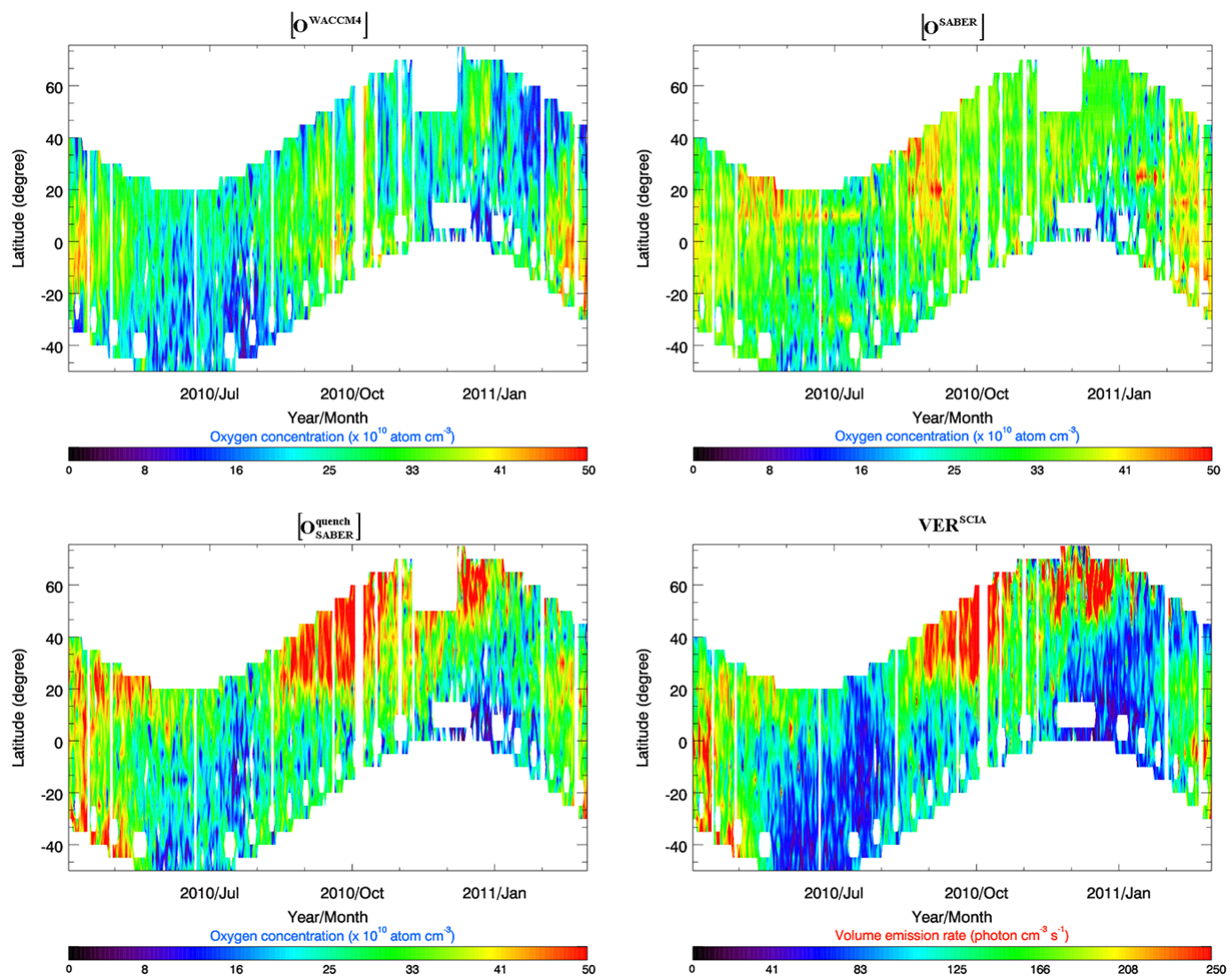

Figure 14. Seasonal variations of daily and vertically averaged (between 85 and $100 \mathrm{~km}$ ) atomic oxygen fields from April 2010 to

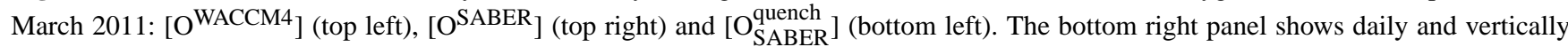
integrated (also from 85 to $100 \mathrm{~km}$ ) SCIAMACHY volume emission rates.

\subsection{Verification step 3}

The Pearson's cross-correlation analysis between the retrieved and the reference $[\mathrm{O}]$ profiles was performed within the time period from April 2010 to March 2011. The calculated correlation coefficients were analyzed using the Fischer $t$ test. Figure 13 shows sample correlation coefficient fields as a function of latitude and altitude for monthly averaged (top row and bottom left panel) and daily averaged (bottom right panel) $[\mathrm{O}]$. Regions with correlation coefficients significant at the $68 \%$ confidence level are indicated by solid contour lines, while areas characterized by lower significance are characterized by dotted contour lines and missing contour labels.

The cross correlation between SCIAMACHY and NLRMSISE-00 [O] profiles (top left panel in Fig. 13) indicates that there exists a phase shift of about $180^{\circ}$ in the seasonal variations in the northern tropical region. In a recent study, Sheese et al. (2011) reported on a similar $180^{\circ}$ phase shift of $\left[\mathrm{O}^{\mathrm{MSIS} 00}\right]$ compared to daytime OSIRIS [O] profile measurements. In addition, Russell et al. (2005) found a $180^{\circ}$ phase shift in the tidal signature in MSIS-90 [O] compared to
WINDII [O] measurements and model simulations with the TIME-GCM model.

The correlation between SCIAMACHY ([O $\left.\left.\mathrm{O}_{\mathrm{WACC} 4}^{\text {quench }}\right]\right)$ and SD-WACCM $\left[\mathrm{O}^{\mathrm{WACCM} 4}\right]$ profiles (top right panel) is characterized by relatively high correlation coefficients of more than 0.65 in large parts of the latitude/height ranges shown. Directly above the equator the correlation is lower, particularly above the $[\mathrm{O}]$ peak.

The correlation coefficient field for monthly averaged $\left[\mathrm{O}_{\mathrm{SABER}}^{\text {quench }}\right]$ vs. $\left[\mathrm{O}^{\mathrm{SABER}}\right]$ does not contain the areas of negative (NRLMSISE-00) or extensive areas with low (SDWACCM4) values that indicate discrepancies of the retrieved $\left[\mathrm{O}_{\mathrm{SABER}}^{\text {quench }}\right]$ compared to $\left[\mathrm{O}^{\mathrm{MSIS} 00}\right]$ or $\left[\mathrm{O}^{\mathrm{WACCM} 4}\right]$. The correlation of $\left[\mathrm{O}_{\mathrm{SABER}}^{\text {quench }}\right]$ with the SABER measurements on a daily basis (bottom right panel) shows a similar pattern than for the monthly averaged data but with lower correlation coefficients, as expected. We notice the presence of relatively high correlation coefficient values in the altitude range 88$95 \mathrm{~km}$ for monthly averaged $\left[\mathrm{O}_{\mathrm{SABER}}^{\text {quench }}\right]$ vs. $\left[\mathrm{O}^{\mathrm{SABER}}\right]$. The distribution of correlation coefficient values for monthly and daily averaged data are quite similar by sight (see bottom left and bottom right panels in Fig. 13). The high correlation 

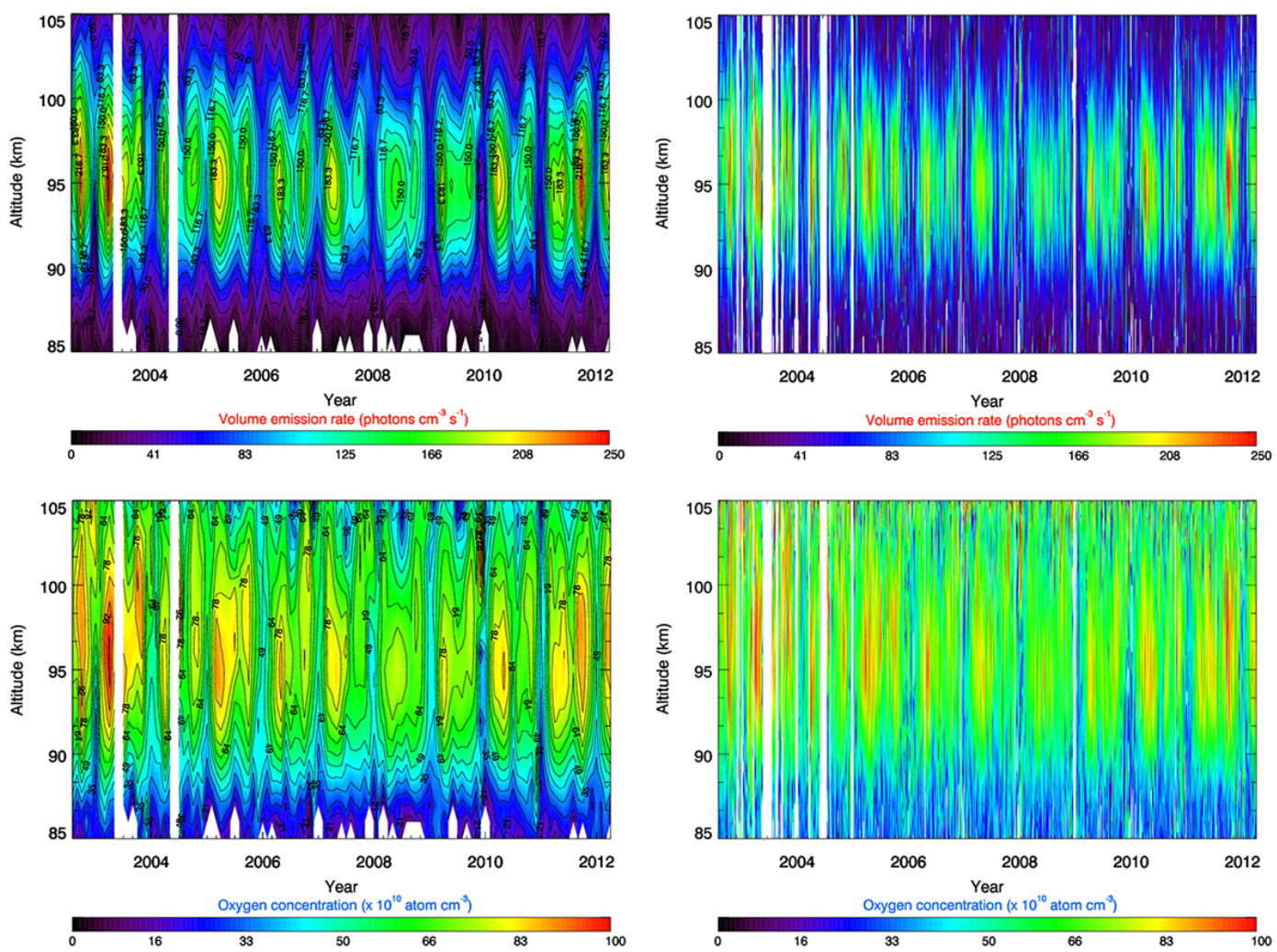

Figure 15. Temporal evolution of VER profiles (top panels) and $\left[\mathrm{O}_{\mathrm{SABER}}^{\text {quench }}\right]$ (bottom panels) with monthly (left panels) and daily (right panels) resolution for the $10-20^{\circ} \mathrm{N}$ latitude range from August 2002 to April 2012.

coefficients in the range $88-95 \mathrm{~km}$ may be related to the fact that the atomic oxygen profile retrievals from SABER and SCIAMACHY measurements are based on different airglow emissions that peak at different altitudes. The SABER nighttime atomic oxygen profiles are retrieved from the Meinel band VER $\left(\mathrm{OH}^{*}\right.$ near $\left.2 \mu \mathrm{m}\right)$ profiles, which peak at about $87 \mathrm{~km}$. In contrast, the $\mathrm{O}$ green line emissions used to retrieve atomic oxygen profiles from SCIAMACHY nighttime measurements peak near $95 \mathrm{~km}$. [O] profiles can only be retrieved well from the different airglow emissions at altitudes with non-negligible emissions. We may therefore expect that the SABER [O] profile retrievals become more and more inaccurate above about $95 \mathrm{~km}$, and the SCIAMACHY becomes more inaccurate below about $87 \mathrm{~km}$.

\subsection{Seasonal variations}

We now present some first sample results on the morphology of atomic oxygen in the MLT region. More detailed analyses of different aspects of the spatiotemporal variability of atomic oxygen will be the foci of future studies.

Figure 14 shows seasonal variations in vertically averaged (85-100 km) SD-WACCM4 (top left panel), SABER (top right panel) and SCIAMACHY (bottom left panel) atomic oxygen for the time period from April 2010 to March 2011, together with vertically averaged green line volume emission rates measured with SCIAMACHY (bottom right panel). When focusing at latitudes close to the equator all panels show a dominating semiannual variation with maxima around the equinoxes. However, there are also differences. The enhanced atomic oxygen abundances seen in the SCIAMACHY data (bottom left panel) in boreal fall and winter at latitudes above $20^{\circ} \mathrm{N}$ - consistent with a similar enhancement in the volume emission rates (bottom left panel) - are not that apparent in the SD-WACCM and SABER data sets. The reason for this discrepancy is currently unknown. We note, however, that similar oxygen anomalies at about $20^{\circ} \mathrm{N}$ in March 2010 and September 2010 are found in SABER and SCIAMACHY atomic oxygen fields but not in modeled $\left[\mathrm{O}^{\text {WACCM4 }}\right]$.

Figure 15 shows contour plots of $\mathrm{O}$ green line volume emission rates (top row) and retrieved atomic oxygen (bottom row) as a function of time and altitude with monthly (left column) and daily (right column) resolution for the $10-20^{\circ} \mathrm{N}$ latitude range and for the entire SCIAMACHY mission period from August 2002 to April 2012. Note that in case of the results for daily averaging (Figs. 14 and 15), gaps in the SABER temperature data set were filled with monthly averaged temperature data. The measurement gaps indicated by white areas in Fig. 15 are a consequence of missing SCIAMACHY raw data during these periods. The VER as well 
as the $\mathrm{O}$ profile data presented in Fig. 15 show evidence for pronounced semiannual - with the well-established equinox maxima - and 11-year solar cycle signatures, with the solar cycle signature being more obvious at altitudes above about $95 \mathrm{~km}$ than below. An annual component is also visible associated with a major minimum in boreal winter and a minor minimum in boreal summer. These signatures are consistent with earlier studies (e.g., Liu and Shepherd, 2008; von Savigny and Lednyts'kyy, 2013) and will be the foci of future investigations of this comprehensive data set of atomic oxygen profiles in the MLT region.

\section{Conclusions}

Atomic oxygen concentration profiles in the MLT region were retrieved from SCIAMACHY observations of the $\mathrm{O}$ green line emission in the terrestrial nightglow. The inversion of integrated LER profiles to VER profiles was performed with a linear least squares minimization technique with regularization. The employed photochemical model is based on the generally accepted two-step Barth transfer scheme and $[\mathrm{O}]$ retrievals were carried out for the standard empirical photochemical model by McDade et al. (1986) as well as for an extended version that also considers quenching of $\mathrm{O}\left({ }^{1} \mathrm{~S}_{0}\right)$ by $\mathrm{O}\left({ }^{3} \mathrm{P}\right)$ or $\mathrm{N}_{2}$.

A comprehensive sensitivity analysis was carried out to determine the effect of various error contributions occurring at the different steps of the [O] profile retrieval. Using the sensitivity analysis results, an error budget for the [O] profile retrievals from SCIAMACHY green line nightglow observations was established based on successive linear addition of the estimated uncertainty components in order to avoid any assumptions concerning distributions of model parameters and other error components. The errors were averaged in the altitude range $90-100 \mathrm{~km}$ and partial contributions of each error component relative to the total error were calculated in percent (added partial errors result in $100 \%$ of the error shown in the last two columns of Tables 3-8 in the supplementary material). At the retrieval step leading to LER profiles (see Sects. 3 and 6.1), the maximum uncertainty calculation includes the effect of errors in tangent height registration (partial contribution of $21.6 \%$ for September 2010 to the total error), limited radiometric accuracy (partial contribution of $31.7 \%$ ) and spectrum integrating uncertainties (partial contribution of $46.7 \%$ ). At the retrieval step resulting in VER profiles (see Sects. 4, 4.3, 6.1 and 7.1) the maximum uncertainty calculation includes the impact of modeling errors (partial contribution of $24.3 \%$ for September 2010), parameter errors (partial contribution of $46.4 \%$ ) measurement errors (partial contribution of $20.6 \%$ ) and smoothing errors (partial contribution of $8.7 \%$ ). At the retrieval step resulting in $[\mathrm{O}]$ profiles (see Sects. 5, 6.2, 7.1), the maximum uncertainty calculation includes the impact of modeling errors (partial contribution of $15.8 \%$ for September 2010), parameter errors (partial contribution of $31.4 \%$ ), measurement errors (partial contribution of $12.1 \%$ ), smoothing errors (partial contribution of $4.3 \%$ ), temperature uncertainty values (partial contribution of $29.8 \%$ ) and density uncertainty values (partial contribution of $6.6 \%$ ).

The retrieved $[\mathrm{O}]$ profiles were compared to simulations with NRLMSISE-00 and SD-WACCM4 and to observations with SABER. The comparisons showed that NRLMSISE$00[\mathrm{O}]$ concentrations are significantly lower than the other ones.

Seasonal variations found in atomic oxygen anomalies in SABER and SCIAMACHY data sets are not so evident in SD-WACCM4 model simulations. The SCIAMACHY [O] profiles are in better agreement with co-located SABER observations when the extended photochemical model - considering quenching of $\mathrm{O}\left({ }^{1} \mathrm{~S}\right)$ by $\mathrm{O}\left({ }^{3} \mathrm{P}\right)$ or $\mathrm{N}_{2}$ - is used. This is an indication that the extended photochemical model is more appropriate to retrieve [O] profiles from the $\mathrm{O}$ green line emission than the standard photochemical model.

The implemented retrieval scheme was applied to the entire SCIAMACHY data set covering the period from August 2002 to April 2012, providing one of the most comprehensive atomic oxygen data sets in the MLT region. This data set will be evaluated in the near future to investigate seasonal, long-term, as well as solar cycle variations, both at the 11-year and 27-day temporal scale. 


\section{Appendix A}

This appendix provides explanations for Table 2 showing upper and lower boundaries of the photochemical model parameters relevant for the retrieval of atomic oxygen profiles from $\mathrm{O}\left({ }^{1} \mathrm{~S}\right)$ green line airglow measurements (see Sect. 5). The maximum and minimum values of $A_{558}$ were taken from the works of Nakayama et al. (2006) $\left(1.26 \mathrm{~s}^{-1}\right)-$ also used by Gao et al. (2012) - and Snively et al. (2010) $\left(1.06 \mathrm{~s}^{-1}\right)$, respectively. The $A_{558}$ values used by McDade et al. (1986) $\left(1.18 \mathrm{~s}^{-1}\right)$, Makhlouf et al. (1998) $\left(1.18 \mathrm{~s}^{-1}\right)$, Semenov (1997) $\left(1.215 \mathrm{~s}^{-1}\right)$ and Khomich et al. (2008) $\left(1.215 \mathrm{~s}^{-1}\right)$ are between these maximum/minimum values.

The maximum and minimum values of $A_{1 \mathrm{~s}}$ were taken from McDade et al. (1986) $\left(1.35 \mathrm{~s}^{-1}\right.$, based on research of Nicolaides et al., 1971) and Snively et al. (2010) $\left(1.105 \mathrm{~s}^{-1}\right)$, respectively. The dimensionless values $\mathrm{C}(0), \mathrm{C}(1)$ and $\mathrm{C}(2)$ correspond to the fitting coefficients $\mathrm{C}^{\prime} / \mathrm{C}^{\prime \mathrm{O}_{2}}, \mathrm{C}^{\prime \mathrm{O}}$ and $\mathrm{C}^{\prime \mathrm{O}_{2}}$ (see McDade et al., 1986), which represent quenching by the different species (the used coefficients typically correspond to multiple reactions represented by the intermediate coefficients; see Table 1). The maximum and minimum values of $\mathrm{C}(0), \mathrm{C}(1)$ and $\mathrm{C}(2)$ used here were taken from McDade et al. (1986).

The rate coefficients are calculated in this study as follows:

$$
\begin{aligned}
& \kappa_{1}=k_{1} \times 10^{-33} \cdot(300 / T)^{2}, \\
& { }^{1} \kappa_{5}={ }^{1} k_{5} \times 10^{-11} \cdot e^{-305 / T}, \\
& { }^{2} \kappa_{5}={ }^{2} k_{5} \times 10^{-17} \text { and } \\
& { }^{3} \kappa_{5}={ }^{3} k_{5} \times 10^{-12} \cdot e^{-\left(812-1.82 \times 10^{-3} \cdot T^{2}\right) / T} .
\end{aligned}
$$

A value of $k_{1}=4.7$ was used for the standard retrieval and the temperature dependence of $\kappa_{1}$ was taken from McDade et al. (1986), as also done by Gao et al. (2012). The uncertainty range of $k_{1}$ (see Table 1 ) was estimated according to the uncertainties typical for the laboratory work performed by Campbell and Gray (1973). In terms of the temperature dependence of ${ }^{1} \kappa_{5}$, we used the same expression as in Semenov (1997), Khomich et al. (2008) and von Savigny and Lednyts'kyy (2013). The uncertainty range of ${ }^{1} k_{5}$ was taken from Slanger and Black (1976) and is also used by Witt et al. (1979). The value of ${ }^{2} \kappa_{5}$ was taken from Okabe (1978) and it is used to calculate the maximum and minimum values by assuming a $10 \%$ uncertainty. Gobbi et al. (1992) and Nakayama et al. (2006) also used a ${ }^{2} \kappa_{5}$ value within $10 \%$ of the Okabe (1978) value. The value of ${ }^{3} k_{5}$, its uncertainty range and the temperature dependence of ${ }^{3} \kappa_{5}$ were taken from Capetanakis et al. (1993), as was done by von Savigny and Lednyts'kyy (2013) as well.

Finally, we note that the temperature dependence of $\kappa_{1}$ and ${ }^{2} \kappa_{5}$ was originally used by McDade et al. (1986) with temperature profiles provided by MSIS-83 atmospheric model. 


\section{The Supplement related to this article is available online at doi:10.5194/amt-8-1021-2015-supplement.}

Acknowledgements. This work was partly funded by Ernst-MoritzArndt-University of Greifswald. SCIAMACHY is jointly funded by Germany, the Netherlands and Belgium. SCIAMACHY Level 1 data was kindly provided by the European Space Agency. We are indebted to the SABER team and NASA for making SABER data available. The authors thank Ian C. McDade (York University, Toronto), Stefan Kowalewski (IUP Bremen) and Martin Kaufmann (Forschungszentrum Jülich) for helpful discussions.

Edited by: F. Khosrawi

\section{References}

Akins, K. A., Healy, L. M., Coffey, S. L., and Picone, J. M.: Comparison of MSIS and Jacchia atmospheric density models for orbit determination and propagation, proceedings of the 13th AAS/AIAA space flight mechanics meeting, Ponce, Puerto Rico, Adv. Astronaut. Sci., 114, 951-970, 2003.

Blackwell, D. E., Ingham, M. F., and Rundle, H. N.: The nightsky spectrum $\lambda \lambda$ 5000-6500 A, Astrophys. J., 131, 15-24, doi:10.1086/146801, 1960.

Bovensmann, H., Burrows, J. P. Buchwitz, M., Frerick, J., Noël, S., Rozanov, V. V., Chance, K. V., and Goede, A. P. H.: SCIAMACHY: mission objectives and measurement modes, J. Atmos. Sci., 2, 127-150, doi:10.1175/15200469(1999)056<0127:SMOAMM>2.0.CO;2, 1999.

Bramstedt, K., Noël, S., Bovensmann, H., Gottwald, M., and Burrows, J. P.: Precise pointing knowledge for SCIAMACHY solar occultation measurements, Atmos. Meas. Tech., 5, 2867-2880, doi:10.5194/amt-5-2867-2012, 2012.

Burrows, J. P., Hölzle, E., Goede, A. P. H., Visser, H., and Fricke, W.: SCIAMACHY - scanning imaging absorption spectrometer for atmospheric chartography, Acta Astronaut., 35, 445-451, doi:10.1016/0094-5765(94)00278-T, 1995.

Campbell, I. M. and Gray, C. N.: Rate constants for $\mathrm{O}\left({ }^{3} \mathrm{P}\right)$ recombination and association with $\mathrm{N}\left({ }^{4} \mathrm{~S}\right)$, Chem. Phys. Lett., 18, 607609,1973

Capetanakis, F. P., Sondermann, F., Höser, S., and Stuhl, F.: Temperature dependence of the quenching of $\mathrm{O}(1 \mathrm{~S})$ by simple inorganic molecules, J. Chem. Phys., 98, 7883, doi:10.1063/1.464596, 1993.

Cardaci, M.: ENVISAT-1 products specifications, vol. 15, SCIAMACHY Products Specifications, available at: http://earth.esa. int/pub/ESA_DOC/ENVISAT/Vol15_Sciamachy_3L_1.1.pdf (last access: 15 March 2014), 2010.

Egerton, A. C.: Lord Rayleigh, 1875-1947, Obit. Not. Fell. R. Soc., 6, 502-538, 1949.

Gao, H., Nee, J.-B., and Xu, J.: The emission of oxygen green line and density of $\mathrm{O}$ atom determined by using ISUAL and SABER measurements, Ann. Geophys., 30, 695-701, doi:10.5194/angeo30-695-2012, 2012.
Garcia, R. R., Marsh, D. R., Kinnison, D. E., Boville, B. A., and Sassi, F.: Simulation of secular trends in the middle atmosphere, 1950-2003, J. Geophys. Res., 112, D09301, doi:10.1029/2006JD007485, 2007.

Gobbi, D., Takahashi, H., Clemesha, B. R., and Batista, P. P.: Equatorial atomic oxygen profiles derived from rocket observations of OI $557.7 \mathrm{~nm}$ airglow emission, Planet. Space Sci., 40, 775-781, 1992.

Gottwald, M., Bovensmann, H., Lichtenberg, G., Noël, S., von Bargen, A., Slijkhuis, S., Piters, A., Hoogeveen, R., von Savigny, C., Buchwitz, M., Kokhanovsky, A., Richter, A., Rozanov, A., Holzer-Popp, T., Bramstedt, K., Lambert, J.-C., Skupin, J., Wittrock, F., Schrijver, H., and Burrows, J. P.: SCIAMACHY Monitoring the Changing Earth's Atmosphere, DLR, Freiburger Graphische Betriebe, 167 pp., 2006.

Hoffmann, C. G., Kinnison, D. E., Garcia, R. R., Palm, M., Notholt, J., Raffalski, U., and Hochschild, G.: CO at 40-80 km above Kiruna observed by the ground-based microwave radiometer KIMRA and simulated by the Whole Atmosphere Community Climate Model, Atmos. Chem. Phys., 12, 3261-3271, doi:10.5194/acp-12-3261-2012, 2012.

Hudson, M. K., Kress, B. T., Mueller, H.-R., Zastrow, J. A., and Blake, J. B.: Relationship of the Van Allen radiation belts to solar wind drivers, J. Atmos. Sol.-Terr. Phys., 70, 708-729, doi:10.1016/j.jastp.2007.11.003, 2008.

Iwagami, N., Shibaki, T., Suzuki, T., Sekiguchi, H., Takegawa, N., and Morrow, W. H.: Rocket observations of atomic oxygen density and airglow emission rate in the WAVE2000 campaign, J. Atmos. Sol.-Terr. Phys., 65, 1349-1360, doi:10.1016/j.jastp.2003.08.002, 2003.

Jursa, A. S.: Handbook of Geophysics and Space Environment, Air Force Research Laboratory, Space Vehicles Directorate, Battlespace Environment Division, 4th Edn., available at: http://www.cnofs.org/Handbook_of_Geophysics_1985/ pdf_menu.htm (last access: 15 March 2014), 1985.

Kaiser, J. W., von Savigny, C., Eichmann, K.-U., Noël, S., Bovensmann, H., Frerick, J., and Burrows, J. P.: Satellite-pointing retrieval from atmospheric limb-scattering of solar UV-B radiation, Can. J. Phys., 82, 1041-1052, doi:10.1139/p04-071, 2004.

Kaufmann, M., Zhu, Y., Ern, M., and Riese, M.: Global distribution of atomic oxygen in the mesopause region as derived from SCIAMACHY O $\left({ }^{1} \mathrm{~S}\right)$ green line measurements, Geophys. Res. Lett., 41, 6274-6280, doi:10.1002/2014GL060574, 2014.

Kennedy, J. J., Rayner, N. A., Smith, R. O., Parker, D. E., and Saunby, M.: Reassessing biases and other uncertainties in sea-surface temperature observations measured in situ since 1850, part 2: biases and homogenisation J. Geophys. Res., 116, D14104, doi:10.1029/2010JD015220, 2011.

Khomich, V. Y., Semenov, A. I., and Shefov, N. N.: Airglow as an Indicator of Upper Atmospheric Structure and Dynamics, Springer, 739 pp., 2008.

Kita, K., Iwagami, K., and Ogawa, T.: Rocket observations of oxygen night airglows: excitation mechanisms and oxygen atom concentration, Planet. Space Sci., 40, 1269-1288, 1992.

Kowalewski, S., von Savigny, C., Palm, M., McDade, I. C., and Notholt, J.: On the impact of the temporal variability of the collisional quenching process on the mesospheric $\mathrm{OH}$ emission layer: a study based on SD-WACCM4 and SABER, Atmos. Chem. Phys., 14, 10193-10210, doi:10.5194/acp-14-10193-2014, 2014. 
Larson, W. J. and Wertz, J. R.: Space Mission Analysis and Design, Microcosm Press and Kluwer Academic Publishers, Springer Netherlands, 920 pp., 1999.

Liu, G. and Shepherd, G. G.: An investigation of the solar cycle impact on the lower thermosphere $\mathrm{O}\left({ }^{1} \mathrm{~S}\right)$ nightglow emission as observed by WINDII/UARS, Adv. Space Res., 42, 933-938, doi:10.1016/j.asr.2007.10.008, 2008.

Liu, H. L., Foster, B. T., Hagan, M. E., McInerney, J. M., Maute, A., Qian, L., Richmond, A. D., Roble, R. G., Solomon, S. C., Garcia, R. R., Kinnison, D., Marsh, D. R., Smith, A. K., Richter, J., Sassi, F., and Oberheide, J.: Thermosphere extension of the whole atmosphere community climate model, J. Geophys. Res., 115, A12302, doi:10.1029/2010JA015586, 2010.

Makhlouf, U. B., Picard, R. H., Winick, J. R., and Tuan, T. F.: A model for the response of the atomic oxygen $557.7 \mathrm{~nm}$ and the $\mathrm{OH}$ Meinel airglow to atmospheric gravity waves in a realistic atmosphere, J. Geophys. Res., 103, 6261-6269, 1998.

McDade, I. C., Murtagh, D. P., Greer, R. G. H., Dickinson, P. H. G., Witt, G., Stegman, J., Llewellyn, E. J., Thomas, L., and Jenkins, D. B.: ETON 2: Quenching parameters for the precursors of $\mathrm{O}_{2}\left(\mathrm{~b}^{1} \sum_{\mathrm{g}}^{+}\right)$and $\mathrm{O}\left({ }^{1} \mathrm{~S}\right)$ in the terrestrial nightglow, Planet. Space Sci., 34, 789-800, 1986.

Melo, S. M. L., Takahashi, H., Clemesha, B. R., Batista, P. P., and Simonich, D. M.: Atomic oxygen concentrations from rocket airglow observations in the equatorial region, J. Atmos. Terr. Phys., 58, 1935-1942, 1996.

Mertens, C. J., Russell, J. M., III, Mlynczak, M. G., She, C.Y., Schmidlin, F. J., Goldberg, R. A., Lopez-Puertas, M., Wintersteiner, P. P., Picard, R. H., Winick, J. R., and $\mathrm{Xu}, \mathrm{X}$.: Kinetic temperature and carbon dioxide from broadband infrared limb emission measurements taken from the TIMED/SABER instrument, Adv. Space Res., 43, 15-27, doi:10.1016/j.asr.2008.04.017, 2009.

Mlynczak, M. G.: Energetics of the mesosphere and lower thermosphere and the SABER experiment, Adv. in Space Res., 20, 1177-1183, doi:10.1016/S0273-1177(97)00769-2, 1997.

Mlynczak, M. G. and Solomon, S.: A detailed evaluation of the heating efficiency in the middle atmosphere, J. Geophys. Res., 98, 10517-10541, doi:10.1029/93JD00315, 1993.

Mlynczak, M. G., Hunt, L. H., Mast, J. C., Marshall, B. T., Russell III, J. M., Smith, A. K., Siskind, D. E., Yee, J.-H., Mertens, C. J., Martin-Torres, F. J., Thompson, R. E., Drob, D. P., and Gordley, L. L.: Atomic oxygen in the mesosphere and lower thermosphere derived from SABER: Algorithm theoretical basis and measurement uncertainty, J. Geophys. Res., 118, 5724-5735, doi:10.1002/jgrd.50401, 2013.

Nakayama, T., Takahashi, K., Matsumi, Y., and Fujiwara, H.: Laboratory study of $\mathrm{O}\left({ }^{1} \mathrm{~S}\right)$ formation process in the photolysis of $\mathrm{O}_{3}$ and its atmospheric implications, J. Atmos. Chem., 53, 107-122, doi:10.1007/s 10874-006-0597-3, 2006.

National Imagery and Mapping Agency: Department of Defense World Geodetic System 1984, Its Definition and Relationships with Local Geodetic Systems, Technical report 8350.2, 2000, available at: http://earth-info.nga.mil/GandG/publications/ tr8350.2/wgs84fin.pdf (last access: 15 March 2014), 2000.

Newell, P. T., Sotirelis, T., Ruohoniemi, J. M., Carbary, J. F., Liou, K., Skura, J. P., Meng, C.-I., Deehr, C., Wilkinson, D., and Rich, F. J.: OVATION: Oval variation, assessment, tracking, in- tensity, and online nowcasting, Ann. Geophys., 20, 1039-1047, doi:10.5194/angeo-20-1039-2002, 2002.

Nicolaides, C., Sinanoğlu, O., and Westhaus, P.: Theory of atomic structure including electron correlation. IV, Method for forbidden-transition probabilities with results for [O I], [O II], [O III], [N I], [N II] and [C I], Phys. Rev. A, 4, 1400-1410, doi:10.1103/PhysRevA.4.1400, 1971.

NOAA: National Geophysical Data Center, Kp/Ap dataset, available at: ftp://ftp.ngdc.noaa.gov/STP/GEOMAGNETIC_DATA/ INDICES/KP_AP/ (last access: 15 March 2014), 2014a.

NOAA: Hemispheric Power Data lists, available at: http://www. swpc.noaa.gov/ftpdir/lists/hpi/ (last access: 15 March 2014), 2014b.

Noël, S., Bovensmann, H., Burrows, J. P., Frerick, J., Chance, K. V., Goede, A. H. P., and Muller, C.: The SCIAMACHY instrument on ENVISAT-1, in: Sensors, Systems, and Next-Generation Satellites II, Vol. 3498 of Proc. SPIE, edited by: Fujisada, H., 94 104, 1998.

NRLMSISE-00: Atmosphere Model, available at: http://ccmc. gsfc.nasa.gov/modelweb/models/nrlmsise00.php (last access: 15 March 2014), 2014.

Okabe, H.: Photochemistry of small molecules, A WileyInterscience publication, ISBN 0-471-65304-7, 1978.

Picone, J. M., Hedin, A. E., Drob, D. P., and Aikin, A. C.: NRLMSISE-00 empirical model of the atmosphere: Statistical comparisons and scientific issues, J. Geophys. Res., 107, 1468, doi:10.1029/2002JA009430, 2002.

Rodgers, C. D.: Characterization and error analysis of profiles retrieved from remote sounding measurements, J. Geophys. Res., 95, 5587-5595, 1990.

Rodgers, C. D.: Inverse Methods for Atmospheric Sounding: Theory and Practice, Series on Atmospheric, Oceanic and Planetary Physics, Vol. 2, World Scientific Publishing, 2000.

Russell, J. M., III, Mlynczak, M. G., Gordley, L. L., Tansock, J., and Esplin, R.: An overview of the SABER experiment and preliminary calibration results, Proc. SPIE, 3756, 277-288, doi:10.1117/12.366382, 1999.

Russell, J. P., Ward, W. E., Lowe, R. P., Roble, R. G., Shepherd, G. G., and Solheim, B.: Atomic oxygen profiles (80 to $115 \mathrm{~km}$ ) derived from wind imaging interferometer/upper atmospheric research satellite measurements of the hydroxyl and greenline airglow: local time - latitude dependence, J. Geophys. Res., 110, D15305, doi:10.1029/2004JD005570, 2005.

SABER: level 2A data (version 2.0), available at: http://saber. gats-inc.com/browse_data.php (last access: 15 March 2014), updated in 2014.

Semenov, A. I.: Long-term changes in the height profiles of ozone and atomic oxygen in the lower thermosphere, Geomagn. Aeronomy+, 37, 354-360, 1997.

Semenov, A. I. and Shefov, N. N.: Model of the vertical profile of the atomic oxygen concentration in the mesopause and lower ionosphere region, Geomagn. Aeronomy+, 45, 797-808, 2005.

Sheese, P. E., McDade, I. C., Gattinger, R. L., and Llewellyn, E. J.: Atomic oxygen densities retrieved from optical spectrograph and infrared imaging system observations of $\mathrm{O}_{2}$ A-band airglow emission in the mesosphere and lower thermosphere, J. Geophys. Res., 116, D01303, doi:10.1029/2010JD014640, 2011. 
Sima, D. M., van Huffel, S., and Golub, G. H.: Regularized total least squares based on quadratic eigenvalue problem solvers, BIT, 44, 739-812, 2004.

Slanger, T. G. and Black, G.: $\mathrm{O}\left({ }^{1} \mathrm{~S}\right)$ production from oxygen atom recombination, J. Chem. Phys., 64, 3767, doi:10.1063/1.432692, 1976.

Smith, A. K., Marsh, D. R., Mlynczak, M. G., Mast, J. C.: Temporal variations of atomic oxygen in the upper mesosphere from SABER, J. Geophys. Res., 115, D18309, doi:10.1029/2009JD013434, 2010.

Snively, J. B., Pasko, V. P., and Taylor, M. J.: OH and OI airglow layer modulation by ducted short-period gravity waves: effects of trapping altitude, J. Geophys. Res., 115, A11311, doi:10.1029/2009JA015236, 2010.

SOST-DLR: Anomaly Reports, available at: http://www.atmos. caf.dlr.de/projects/scops/instrument_monitoring/anomaly_ reports_actual.html (last access: 15 March 2014), updated on 10 May 2012.

SOST-DLR, data quality - thermal performance, available at: http://www.atmos.caf.dlr.de/projects/scops/instrument monitoring/data_quality_thermal.html (last access: 15 March 2014), updated on 30 January 2013a.

SOST-DLR: data quality - pointing (2008-2012) performance, available at: http://www.atmos.caf.dlr.de/projects/scops/ instrument_monitoring/data_quality_pointing_2008_2012.html (last access: 15 March 2014), updated on 31 January $2013 \mathrm{~b}$.

SOST-DLR: Data quality - pointing (2002-2007) performance, available at: http://www.atmos.caf.dlr.de/projects/scops/ instrument_monitoring/data_quality_pointing_2002_2007.html (last access: 15 March 2014), updated on 31 January 2013c. von Savigny, C. and Lednyts'kyy, O.: On the relationship between atomic oxygen and vertical shifts between $\mathrm{OH}$ Meinel bands originating from different vibrational levels, Geophys. Res. Lett., 40, 1-5, doi:10.1002/2013GL058017, 2013.

von Savigny, C. H. A., McDade, I. C., Shepherd, G. G., and Rochon, Y.: Lower thermospheric nitric oxide concentrations derived from WINDII observations of the green nightglow continuum at $553.1 \mathrm{~nm}$, Ann. Geophys., 17, 1439-1446, doi:10.1007/s00585999-1439-9, 1999.

von Savigny, C., Bovensmann, H., Bramstedt, K., Dikty, S., Ebojie, F., Jones, A., Noël, S., Rozanov, A., and Sinnhuber, B.-M.: Indications for long-term trends and seasonal variations in the SCIAMACHY Level 1 version 6.03 tangent height information, Techn. Note IUP scia pointing 2009-01, Issue 2, University of Bremen, Bremen, Germany, 2009.

Wang, Y. F. and Yuan, Y. X.: A trust region algorithm for solving distributed parameter identification problem, J. Comp. Mathem., 21, 759-772, 2003.

Witt, G., Stegman, J., Solheim, B. H., and Llewellyn, E. J.: A measurement of the $\mathrm{O}_{2}\left(\mathrm{~b}^{1} \Sigma_{g}^{+}-X^{3} \Sigma_{g}^{-}\right)$atmospheric band and the $\mathrm{OI}\left({ }^{1} \mathrm{~S}\right)$ green line in the nightglow, Planet. Space Sci., 27, 341350, 1979.

Yoshimura, R., Iwagami, N., and Oyama, K.-I.: Rocket measurement of electron density and atomic oxygen density modulated by atmospheric gravity waves, Adv. Space Res., 32, 837-842, doi:10.1016/S0273-1177(03)00422-8, 2003. 